\title{
APORTES A LA FARMACOPEA DE LOS CERRITEROS PREHISPANICOS DE LA CUENCA DEL RÍO DE LA PLATA
}

\section{CONTRIBUTIONS TO THE PHARMACOPEA OF THE PREHISPANIC CERRITEROS OF THE RÍO DE LA PLATA BASIN}

\author{
Elena CASTIÑEIRA LATORRE ${ }^{1}$ y Carola CASTIÑEIRA LATORRE ${ }^{2}$ \\ ${ }^{1}$ Centro Universitario Regional del Este, Universidad de la República. Tacuarembó s/n, Maldonado, Uruguay. \\ ${ }^{2}$ CONICET, Museo Argentino de Ciencias Naturales "Bernardino Rivadavia" y Museo de La Plata. Av. Angel Gallardo 470, C1405 DJR, Buenos \\ Aires Capital Federal, Argentina. E-mail: carolacl2004@gmail.com
}

\section{Resumen}

Submitted: 03/03/2020; Accepted: 25/05/2020

La presencia de estructuras monticulares en tierra, conocidas como "cerritos" caracterizan el paisaje arqueológico del sur de la cuenca del Río de La Plata y de la cuenca de la Laguna Merín. Los constructores y ocupantes prehispánicos de los cerritos, desarrollaron en estos sitos monticulares, múltiples actividades cotidianas y eventuales de subsistencia particular o grupal. Estas actividades, se reconocen mediante el estudio de evidencias orgánicas e inorgánicas halladas en las secuencias sedimentarias constitutivas de los cerritos y en los artefactos recuperados en estos. En este trabajo, inferimos posibles prácticas asociadas al mantenimiento y cuidado de la salud, a partir de las evidencias macro y micro vegetales recuperadas en los sitios monticulares de las áreas mencionadas y asociamos la información, con los usos medicinales destacados en la literatura etnobotánica regional. Implementamos técnicas estadísticas para procesar los datos antracológicos, carpológicos, fitolíticos y de almidones procedente de muestras de sedimentos, contenedores cerámicos (vasijas y cuchara) e instrumentos líticos (manos de moler y morteros) que fueron dados a conocer en las publicaciones arquebotánicas. Reportamos 32 familias botánicas, de las cuales, un $84 \%$, son destacadas por sus usos medicinales en la literatura etnobotánica regional. Los usos más conspicuos plausibles de ser asociados a este registro estarían vinculados al tratamiento de infecciones, seguido por taxa con propiedades para intervenir en el sistema gastrointestinal. El orden de esta asociación difiere entre los registros procedentes de los cerritos del sistema de humedales del área deltaica del río Paraná, respecto a las restantes áreas geográficas consideradas del nordeste argentino, noreste y este de Uruguay. Contextualizamos nuestros resultados con los datos bioarqueológicos referidos para las poblaciones cerriteras de las áreas consideradas con la vulnerabilidad hidrometeorológica de las mismas.

Palabras-clave: Cerritos, Holoceno, registro paleobotánico, usos medicinales

\begin{abstract}
Archaeological landscapes of southern Río de la Plata and Laguna Merín basins are characterized by the presence of anthropogenic mounds. In these mounds, prehispanic builders and occupants had developed multiple ordinary and daily activities for their particular or grupal subsistence. These activities are recognized through the study of organic and inorganic evidence found in the sedimentary sequences of the mounds as well as in the artifacts recovered from them. In this work we analyzed the vegetal evidences recovered in the sediments and artifacts in order to infer the activities associated to health care, and we correlated this information with that presented by the ethnobotanical literature. We were able to recognize 32 botanical families based on statistical analyses developed with anthracological, carpological, phytolytic, and starch grain data provided by archaeological publications. In this context, $84 \%$ of the identified botanical families have medicinal properties according to the native and traditional pharmacopoeia of the region. The largest number of the botanical families identified here could have been used for infections and gastrointestinal disorders. These therapeutic interventions vary according to whether the records come from the mounds of the wetland system at the delta area of the Paraná River or of the continental areas of the northeastern Argentina, northeast, and east of Uruguay. We discussed our results in the context of the bioarcheological data already provided for the cerriteras populations of the studied region; and in order to understand the differences found, we assessed the hydrometorological vulnerability of the geographic studied areas.
\end{abstract}

Key- words: mound building, Holocen, paleobotanical proxy, medicinal uses 


\section{INTRODUCCIÓN}

El paisaje de los humedales del sureste de la cuenca del Río de la Plata y del litoral atlántico de Uruguay (en adelante SUCURPLA), se caracteriza por la presencia de estructuras monticulares de tierra que construyeron los habitantes prehistóricos. Este registro arqueológico es compartido con las principales cuencas hidrológicas que surcan las Tierras Bajas Sudamericanas (BONOMO et al., 2019; DURÁN y BRACCO 2000; ERICKSON, 2006; LOPEZ et al., 2016; ROSTAIN, 2012). Particularmente, en la literatura arqueológica generada en SUCURPLA, las estructuras monticulares prehispánicas son generalmente referidas como "cerritos" (CAPDEPONT y PINTOS, 2002; CASTIÑEIRA et al., 2014, 2015; LOPEZ et al., 2016; POLITIS y BONOMO, 2012).

El origen de la modalidad constructiva en la SUCURPLA, se ubica en torno a los 5000 años ${ }^{14} \mathrm{C}$ A.P., de acuerdo con los fechados radiocarbónicos obtenidos para los cerritos emplazados en el sector sureste de la macro región definida (Ex.: BRACO et al., 2008, 2011, 2015).Durante el Holoceno tardío y próximo a los 2000 años ${ }^{14} \mathrm{C}$ A.P., la construcción de montículos fue una estrategia extendida para el desarrollo de múltiples actividades, siendo definidos arqueológicamente como sitios multifuncionales (BRACCO, 2006; GIANOTTI y BONOMO 2013; IRIARTE, 2007a; LÓPEZ, 2001; NAUE, 1973; POLITIS y BONOMO, 2012).

De la expansión temporal y espacial del fenómeno cerritos y de su abandono, próximo a los 300 años ${ }^{14} \mathrm{C}$ A.P. dan cuenta las cronologías obtenidas en el marco de las investigaciones desarrolladas en la SUCURPLA (BONOMO et al., 2011b, 2019; BRACCO, 2006; BRACCO у URES, 1999; CABRERA, 2013; CAPDEPONT et al., 2016; CASTIÑEIRA et al., 2014, 2017a, 2017b; CASTRO y CASTIÑEIRA, 2017; DEL PUERTO et al., 2012; GIANNOTTI y BONOMO, 2013; IRIARTE, 2007a, 2007b; LÓPEZ, 2001; LOPONTE et al., 2016; MILHEIRA et al., 2019; POLITIS y BONOMO, 2018).

La mayoría de los cerritos en la SUCURPLA, preservan morfologías semi-circulares, elípticas, de alturas variables, promediando los $2 \mathrm{~m}$. Aunque, existen montículos que alcanzan los $6 \mathrm{~m}$ de altura, así como también, de tan solo $0.50 \mathrm{~m}$. (APOLINAIRE y BASTOURRE, 2016; BRACCO et al., 2015). La presencia de las estructuras, en la macroregión, se concentra en el nordeste argentino, en la zona del delta del río Paraná (BONOMO et al., 2010; POLITIS y BONOMO, 2018) y desembocadura del río Gualeguaychú (CASTRO, 2017). En el este de Uruguay, en el sector sur de la cuenca de la Laguna Merín (BRACCO et al., 2015) y en el noroeste, en la cuenca del río Tacuarembó (GIANOTTI y BONOMO, 2013). En territorio uruguayo, conforman complejos agrupamientos de decenas de estructuras, aunque también, se distribuyen de forma aislada o en conjuntos de a dos y tres montículos (BRACCO et al., 2015; CAPDEPONT et al., 2016). Este último tipo de distribución, es característico en las islas del delta del río Paraná y en general, del nordeste argentino (APOLINAIRE y BASTOURRE, 2016; BONOMO et al., 2011b).

La multiplicidad de proxies (geomorfológicos, topográficos, geológicos, biocomposicionales, cronológicos, arqueológicos) a los cuales se ha recurrido para caracterizar a los cerritos, permite definirlos como geoformas acrecionales de génesis antrópica que contienen evidencias de actividades domésticas, rituales, productivas y extractivas (BRACCO et al., 2019a, 2019b; CASTIÑEIRA et al., 2014, 2015; CASTRO DEL PAPA, 2015; MILHEIRA et al., 2019; POLITIS et al., 2011). El registro de la variabilidad de actividades desarrolladas por los "cerriteros", término empleado por Meirelles (2017) y Milheira et al. (2019) para sus constructores y/u ocupantes, tiene evidencias macro y microscópicas que son recuperadas del interior de las secuencias sedimentarias. Entre estos registros, se destacan los productos y desechos de los desarrollos tecnológicos vinculados a la explotación de los recursos geológicos (industria lítica y cerámica), recursos faunísticos y vegetales (BASTOURRE, 2014; BONOMO, 2012; BONOMO et al., 2012, 2014; CAPDEPONT et al., 2005, 2016; DEL PUERTO et al., 2016; DI PRADO y CASTRO, 2014; GASCUE y LOPEZ, 2009; GIANOTTI, 2000; INDA y DEL PUERTO, 2007; POLITIS y BONOMO, 2018). Asimismo, en algunos casos, al interior de las estructuras, tanto en la cima, en sus laterales, o periferias, se han recuperado restos óseos humanos en simples y complejas disposiciones, o tan solo, fragmentos aislados (CABRERA, 1999; CAPDEPONT y PINTOS, 2002; FIGUEIRO, 2014; GIANOTTI y LÓPEZ, 2009; KOZAMEH et al., 2018; SANS, 1999; SCABUZZO et al., 2015; SCABUZZO y RAMOS, 2018). Las investigaciones bioarqueológicas desarrolladas a partir de estos registros, permiten reconocer el estado sanitario de los cerriteros prehispánicos (FIGUEIRO, 2014; SCABUZZO et al., 2015; SCABUZZO y RAMOS, 2018) y dado las paleopatologías inferidas, podemos considerar que estas poblaciones debieron concebir 
estrategias terapéuticas para el mantenimiento de la salud y de las dolencias. Nos proponemos explorar la participación que pudieron tener los recursos botánicos en el desarrollo de dichas estrategias.

Enmarcándonos en la etnobotánica, nos centramos en la adscripción de los cerritos como unidades domésticas. En etnobotánica, los registros procedentes y/o asociados a las unidades domésticas, son los que promueven el desarrollo de análisis comportamentales, cuyos resultados, habilitan interpretaciones generalistas para describir la vida grupal (GOODY, 1972; HERNÁNDEZ et al., 2015). Acorde a esto, cada cerrito conformará nuestra unidad de análisis para reconocer las estrategias fitoterapéuticas desarrolladas por los cerriteros de la macro región definida.

El rol de los recursos botánicos en la arqueología de cerritos, ha estado fundamentalmente abordados por estudios arqueobotánicos vinculados al análisis de silicofitolitos, almidones, carbones, semillas y partículas carbonosas (BONOMO et al., 2010, 2012, 2017; BREA et al., 2013; CASTRO, 2017; CAPDEPONT et al., 2002, 2005; COLOBIG et al., 2015; DEL PUERTO et al., 2016a, 2016b; DEL PUERTO y INDA, 2005; INDA y DEL PUERTO, 2007; IRIARTE, 2003; IRIARTE et al., 2001; LÓPEZ et al., 2014a; SANCHEZ et al., 2013). En su mayoría, las evidencias que conforman estos registros, fueron recuperadas de las secuencias sedimentarias y también, de los restos adheridos a las paredes y/ o filos de los instrumentos líticos y cerámicos. Estas investigaciones, han contribuido al reconocimiento de las prácticas vinculadas a la producción y consumo de alimentos, fabricación y mantenimiento de herramientas, construcción y acondicionamiento de espacios, generación y preservación de fuegos y aunque, en menor medida, a inferir posibles prácticas asociadas al mantenimiento y cuidado de la salud. Para ello, algunos trabajos (CAPDEPONT et al., 2005; DEL PUERTO, 2011; DEL PUERTO et al., 2016a, 2016b; LÓPEZ et al., 2014a; TRILLO et al., 2011), han recurrido a las crónicas históricas que documentan las prácticas "nativas" durante los primeros años de la colonización europea y a investigaciones etnográficas más recientes, recogiendo los saberes ancestrales. Este nuevo aporte, pretende dar continuidad a la reflexión y desarrollo de conocimiento relacionado al uso de los recursos botánicos por parte de poblaciones prehispánicas, utilizando para ello, el registro arqueológico como documento testimonial. La conjunción de los datos arqueobotánicos con los procedentes de la etnografía o etnobotánica, están siendo aplicados en investigaciones paleofarmacológicas en Sudamérica (CHAVEZ y REINHARD, 2003; DE SOUZA y BARBERI, 2005; REINHARD, 2000; REINHARD et al., 1991), no solo para identificar y describir las plantas medicinales usadas por las poblaciones prehispánicas, sino que también, para avanzar en el reconocimiento de las propiedades farmacológicas de las especies nativas para la industria farmacéutica actual (REINHARD, 2000). Tomando de referencia dos axiomas claves en el desarrollo de la paleofarmacología:

"Every prehistoric culture had some sort of healthcare system, and a pharmacopoeia was integral in each ancient cultural system." "In theory, the archaeological record can be used to identify medicinal plants used in ancient times." (REINHARD, 2000: 443).

Evaluamos la presencia de evidencias macro (carbones y semillas) y microbotánicas (silicofitolitos y almidones) reportadas por las investigaciones arqueológicas desarrolladas en los cerritos del este de Uruguay (cuenca de la Laguna Merín, Laguna de Castillos y Laguna Negra) y noreste (cuenca del río Tacuarembó), Delta del río Paraná - Argentina y margen occidental del bajo río Uruguay - Argentina (Figura 1). Analizamos la presencia de los micro y macro restos reportados para los depósitos sedimentarios y de los adheridos a las paredes de los contenedores cerámicos (vasijas y cuchara) e instrumentos líticos (piedras de moler). Asociamos las evidencias arqueobotánicas reconocidas en los registros mencionados, a las propiedades terapéuticas de las taxa botánicas, de acuerdo a lo reconocido por la literatura etnobotánica, en la cual, se registran, listan y describen las plantas nativas y los usos que tradicionalmente han participado en la vida de los habitantes de la macroregión (ALONSO y DESMARCHELIER, 2015; ARRILLAGA DE MAFFEI, 1997; CASTIÑEIRA et al., 2018, 2020; DEL PUERTO, 2011; HERNANDEZ et al., 2009; LAHITTE et al., 1998; SCARPA y ROSO, 2019). De esta forma, comenzaremos a explorar regularidades y tendencias en una escala temporal y espacial extendida de la presencia de algunos recursos botánicos, cuyas propiedades terapéuticas son amplia y formalmente reconocidas. En este sentido, discutiremos nuestro aporte al conocimiento de una farmacopea nativa (sensu definición proporcionada por 
ARENAS, 2009) en la SUCURPLA, ampliando el reconocimiento de la interacción: cultura/diversidad botánica.

\section{Características de los cerritos y de sus áreas de emplazamiento}

La presencia, función y origen de los cerritos ha marcado la historia arqueológica de la región. Hacia finales del siglo XIX y principios del XX, las primeras interpretaciones acerca del rol de los cerritos versaban en la correlación emplazamiento - área inundable (AMEGHINO, 1880-1881; ARECHAVALETA, 1892; BAUZÁ, 1895; FIGUEIRA, 1892; TORRES, 1903, 1911; ZEBALLOS, 1878). Aunque, también, eran reconocidos como estructuras construidas por los "primitivos habitantes" para enterrar a sus muertos (LISTA, 1878; ROTH, 1888). De algunos de los trabajos que dan cuenta de los marcos interpretativos en la arqueología sistémica de los cerritos de la SUCURPLA (BRACCO et al., 2015; CAPDEPONT et al., 2016; CASTIÑEIRA et al., 2014; SUÁREZ, 2006), podemos sintetizar que: durante el siglo XX fue dominante el aporte de resultados y discusión en cuanto a establecerlos como áreas domésticas en zonas inundables y/o áreas formales de enterramiento. Durante los primeros años del siglo XXI, se integran los marcos interpretativos referidos a la complejidad social que debieron alcanzar las sociedades constructoras de cerritos para visibilizar sus áreas de asentamientos y ritualidad. Así, se exponen los conceptos de monumentalidad, formación aldeana y la correlación con los caracteres que defienden al formativo mesoaméricano (GIANOTTI, 2000, 2015; IRIARTE, 2003, 2007). Más recientemente, Bracco et al. (2019a) asocian el origen y función de los cerritos de una localidad arqueológica del este de Uruguay, con el uso de hornos de pozo para el procesamiento de alimentos.

El eje de la discusión actual referente a los cerritos en la SUCURPLA, se centra en el grado de intencionalidad en la acción, planificación y evolución constructiva ((BONOMO et al., 2011b; BRACCO, 2006; BRACCO et al. 2019a, 2019b; CASTIÑEIRA et al., 2013, 2016, 2017a, 2017b; LOPONTE et al., 2016). Esto es, si la génesis y evolución acrecional responde a la concentración voluntaria o involuntaria de desechos generados durante la ocupación de una localidad. $\mathrm{O}$, a una ingeniería constructiva, que planificó y consensuo, estrategias para elevar y mantener áreas, en las cuales, fueron desarrolladas diferentes actividades relacionadas con su ocupación, producción (de herramientas, de alimentos, cultivos) y en algunos casos, de legitimación hereditaria de paisajes macrofamiliares (CASTRO y CASTIÑEIRA, 2018; LÓPEZ, 1999). Este último marco interpretativo, está sustentado desde evidencias: topográficas, estratigráficas, sedimentológicas, mineralógicas, micromorfológicas, paleobotánicas, cronológicas y genéticas, para diferentes localidades arqueológicas de la SUCURPLA (BONOMO, 2012; BONOMO et al., 2019; CASTIÑEIRA et al., 2015, 2016; CASTIÑEIRA y PIÑEIRO, 2002; DEL PUERTO et al., 2016b; FIGUEIRO, et al., 2017; GIANOTTI et al., 2005), las cuales, permiten inferir que, para erigir cerritos, existieron diversas estrategias (Figura 2). Una, fue seleccionar y acumular sedimentos extraídos de los horizontes del suelo circundante (BRACCO et al., 2000), generando, en algunos casos, áreas topográficas negativas (GIANOTTI y BONOMO, 2013; LÓPEZ y CASTIÑEIRA, 2001). Otra estrategia, habría implicado la selección y transporte de sedimentos desde lugares distantes del área de emplazamiento y/o una combinación de ambas, intra-localidad e intra-sitio (CASTIÑEIRA y PIÑEIRO, 2000; CASTIÑEIRA et al., 2013, 2017a, 2017b). En algunos casos, para acrecentar volumétricamente y otorgarles solidez estructural, le agregaron a los sedimentos, materiales orgánicos e inorgánicos de diversos orígenes, tamaños y proporciones (BRACCO, 2019a, 2019b; CASTIÑEIRA y PIÑEIRO, 2000; CASTIÑEIRA et al., 2015, 2016; CASTRO y CASTIÑEIRA, 2018; POLITIS et al., 2011; BRACCO, 2019a). Ahora bien, en lo que hay mayor consenso, en la literatura referente a los cerritos de la SUCURPLA, es que los cerritos, fueron ocupados, y en ellos, los cerriteros desarrollaron múltiples actividades cotidianas y eventuales de subsistencia particular y grupal.

Los registros arqueobotánicos analizados en este trabajo, proceden de los cerritos que se distribuyen en diferentes áreas del SUCURPLA, asociadas al dominio de los humedales. Los humedales, constituyen superficies cubiertas de agua (permanente o temporal) cuya variabilidad hidrológica es dependiente de los cambios climáticos y/o al control antrópico. Contempla a las zonas ribereñas que acompañan al espejo de agua, a las costas adyacentes y a las islas, o a las extensiones de agua marina (CONVENCIÓN RAMSAR, 1971). La influencia de las mareas, determina la diferenciación entre humedales marinos y costeros de los continentales, estos últimos, asociados a los corredores fluviales. En el sistema de humedales marinos y costeros se ubican los cerritos del este de Uruguay (sitios: Id: 1 a Id: 9 en Tabla 1 y Figura 1). En los sistemas de humedales continentales, se 
emplazan los de la cuenca del río Tacuarembó (Id: 11 y 12 en Tabla 1 y Figura 1), los de la margen occidental del bajo río Uruguay (Id: 20 en Tabla 1, Figura 1) y los cerritos del Delta del Paraná (Id:13 a 18 en Tabla 1, Figura 1). Ambos sistemas de humedales, se enmarcan en la ecorregión denominada: los pastizales del Río de La Plata (sensu SORIANO, 1991), cuya vinculación dendroflorística con la flora paranaense y la flora chaqueña, incide en su inclusión como "región de transición ChaqueñoParanaense" (sensu BRUSSA y GRELA, 2007). En esta región transicional y expensas de un clima mesotérmico de gradiente laxo (BILENCA y MIÑARRO, 2004), predominan en las planicies de inundación herbazales y bosques xerófilos (CHEBATAROFF, 1980).

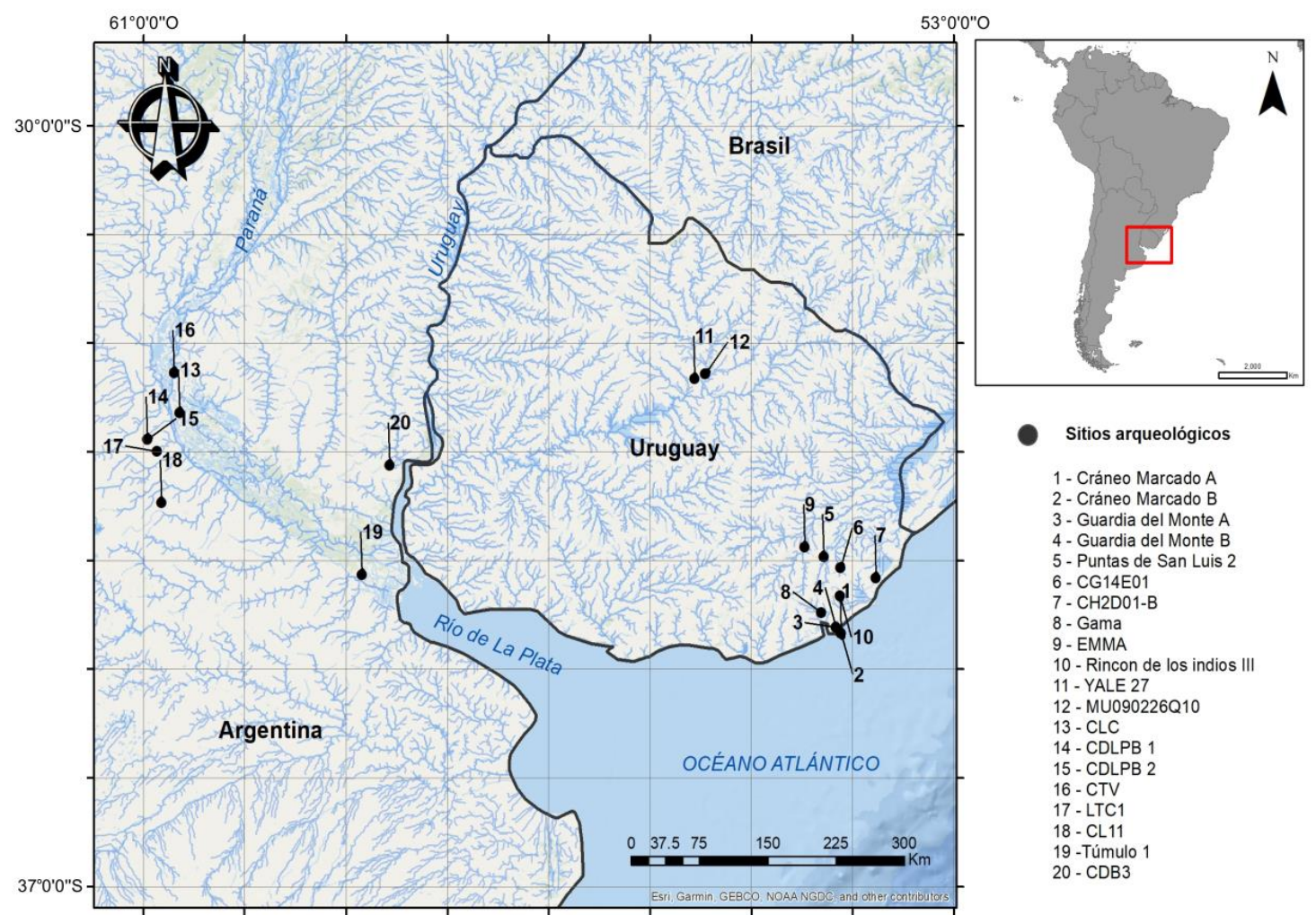

Figura 1. Región definida como SUCURPLA con los sitios monticulares: Cerritos (unidad de análisis) de donde proceden las evidencias arqueobotánicas analizadas.

\section{Localidades arqueológicas en los Humedales del este de Uruguay (HEU)}

El registro arqueológico de los cerritos emplazados en los HEU, han sido referentes para sustentar diferentes estadios en el desarrollo sociocultural de las Tierras Bajas Sudamericanas (BRACCO et al., 2008; IRIARTE et al., 2004, 2007b; LÓPEZ et al., 2004). Conforman al presente, la región nodal, para reconocer la antigüedad de la modalidad constructora de cerritos en la SUCURPLA (BRACCO, 2006).

Los paisajes de HEU se extienden desde $c a .31^{\circ}$ a los $34^{\circ} \mathrm{S}$ y desde $52^{\circ}$ a los $54^{\circ} \mathrm{O}$ (Figura 1) y se caracteriza por un sistema de serranías, planicies de inundación, campos de dunas y lagunas costeras próximas al litoral atlántico. El sistema de serranías se desarrolla desde los $200 \mathrm{msnma}$ (metros por encima del nivel actual del mar) hasta los $450 \mathrm{msnm}$. El ecosistema predominante es la pradera, dominada por gramíneas y leguminosas asociadas a la presencia de especies herbáceas y arbustos xerófitos, los cuales, caracterizan al bosque serrano (TORANZA et al., 2018). En cotas $c a$. los $100 \mathrm{msnm}$, se desarrollan colinas con crestas rocosas y lomadas. Este paisaje está recortado por cursos de agua con desarrollo de "bosque fluvial", denominado también como "monte ribereño" (BRAZEIRO, 2018; BRUSSA y GRELA, 2007). Por debajo de $50 \mathrm{msnm}$ se desarrolla el sistema de planicies, en las cuales Butia odorata (Barb.Rodr.) Noblick, forma extensos palmares. También, se destacan los bañados, los que constituyen cuerpos de agua semi-permanente o temporarios, colonizados por vegetación palustre y en cuyos márgenes se establecen especies arbóreas (DANGAUS, 2005). Finalmente, el paisaje costero del litoral atlántico de Uruguay, se distingue por 
un sistema de campos de dunas y lagunas costeras, playas y afloramientos rocosos. En los campos de dunas, predominan la vegetación xerófila con presencia de matorrales espinosos, en tanto que en las lagunas y bañados interdunares, se desarrollan praderas con bosques y matorrales espinosos psamófilos (ALONSO y BASSAGODA, 1999; FAGÚNDEZ y LEZAMA, 2005).

De la unidad planicies de mareasde HEU, contamos con los registros arqueobotánicos, procedentes de los cerritos emplazados en: Laguna de Castillos (LgC) y la laguna Negra. De la unidad planicie fluvial, los procedentes de los sitios de la margen del río San Luis. Del sistema de sierras, los datos procedentes de los emplazados en la sierra de San Miguel y sierra de los Ajos (Figura 1, Tablas 1 y 2).

Las localidades arqueológicas emblemáticas en la LgC son: Cráneo Marcado (CM) y Guardia del Monte (GM) (Figura 1, Tabla 1). CM, se encuentra en la margen oeste de la laguna y se caracteriza por tres cerritos y un sitio somero multi-componente emplazado en una cresta bioclástica próxima a la costa lagunar (CAPDEPONT et al., 2016). La secuencia cultural para los cerritos de LgC tiene cronologías radiocarbónicas tempranas $c a$. $\operatorname{los} 3000$ años ${ }^{14} \mathrm{C}$ A.P. y tardías, con evidencias materiales de los siglos XVII - XVIII, pos-conquista europea (CAPDEPONT y PINTOS, 2006). Las evidencias botánicas que hemos incluido en nuestra base de datos corresponde a las taxa arqueobotánicas reportadas en Capdepont et al. (2002) (Tabla 2) de los análisis fitolíticos desarrollados en las superficies internas y externas de los contenedores cerámicos procedentes de los cerritos A y B y de los sedimentos constitutivos de ambos sitios. Por su parte, la localidad arqueológica GM, emplazada en la margen este de la laguna, se caracteriza también, por la presencia de tres cerritos y un sitio somero en crestas bioclástica (CAPDEPONT et al., 2016). La secuencia cultural de los cerritos de $\mathrm{GM}$, tiene una cronología radiocarbónica temprana $c a$. $\operatorname{los} 2300$ años ${ }^{14} \mathrm{C}$ A.P. y dos fechados en torno a los 1200 años ${ }^{14}$ C A.P. (CAPDEPONT y PINTOS, 2006; CAPDEPONT et al., 2016; Tabla 1). Las evidencias arqueobotánicas de esta localidad (Tabla 2), proceden de los análisis de fitolitos desarrollados en las superficies de seis piedras de moler del cerrito A (Id.1 en Tabla 1) y dados a conocer en Capdepont et al. (2005). También, incluimos las taxa arqueobotánicas reconocidas para la matriz sedimentaria de los cerritos A y B (Id.3 e Id.4 en Tabla 1), publicadas en del Puerto et al. (2016) (Tabla 2).

Otra cuenca lagunar de alto interés arqueológico es la Laguna Negra. Se le atribuye a esta cuenca, una incidencia estratégica en el desarrollo de la conectividad social entre las tierras bajas y la costa atlántica (LÓPEZ et al., 2011, 2014b; LÓPEZ y GIANOTTI, 2001). En su flanco norte, se emplaza la localidad arqueológica: Rincón de Los Indios (Tabla 1, Figura 2). Esta localidad, se caracteriza por la presencia de cuatro cerritos y microrelieves también antrópicos. La génesis de estas construcciones se sitúa $c a$. los 3000 años ${ }^{14}$ CA.P. y tienen como edad más tardía $c a .700$ años ${ }^{14}$ CA.P. (GIANOTTI y LOPEZ, 2009; LÓPEZ y GASCUE, 2009). Los datos arqueobotánicos analizados de esta localidad, proceden de la identificación de los silicofitolitos contenido en la matriz sedimentaria del sitio Id. 7 III (Tabla 2) y de los granos de almidón, reportado también, para la matriz del mismo sitio, por Iriarte (2001).

En la planicie fluvial de los HEU se ubica la localidad arqueológica Puntas de San Luis (PSL) (Figura 1) asociada al dominio de pradera, palmares y parches de bosque ribereño (INDA y DEL PUERTO, 2007). Arqueológicamente, la localidad PSL, se caracteriza por la presencia de 15 estructuras monticulares (BRACCO et al., 2008). Cuatro de estos cerritos, han sido intervenidos por diferentes muestreos y excavaciones que han permitido reconocer, una ocupación temprana de la localidad ca. 4000 años ${ }^{14}$ CA.P. (BRACCO et al., 2008). Para este trabajo, integramos el registro de restos leñosos carbonizados recuperados en uno de los cerritos (Id.5, Tabla 1), reportado por Inda y del Puerto (2007) y cuyas cronologías son informadas en la Tabla 1. 
Tabla 1: Referencias generales de las unidades de análisis. Los fechados radiocarbónicos de los sitios corresponden a la edad máxima (arriba) y mínima (abajo) calibradas a $1 \sigma$ con el programa Calib Rev 7.0.4 (STUIVER y REIMER, 1993).

\begin{tabular}{|c|c|c|c|c|c|c|c|}
\hline $\begin{array}{l}\text { Región de } \\
\text { Humedales }\end{array}$ & Área & Localidad & Sitio & $\begin{array}{c}\begin{array}{c}\text { Localización } \\
\text { aprox. en } \\
\text { coordenadas }\end{array} \\
\end{array}$ & $\begin{array}{l}\text { Edades }{ }^{14} \mathrm{C} \text { A.P. } \\
\text { [cal. } 1 \sigma \mathrm{AD} / \mathrm{BC} \text { ] }\end{array}$ & Referencia & $\begin{array}{c}\text { ID en este } \\
\text { trabajo }\end{array}$ \\
\hline \multirow{10}{*}{$\begin{array}{l}\text { Humedales } \\
\text { del Este de } \\
\text { Uruguay }\end{array}$} & \multirow{4}{*}{$\begin{array}{l}\text { Laguna de } \\
\text { Castillo }\end{array}$} & \multirow{2}{*}{$\begin{array}{l}\text { Cráneo } \\
\text { Marcado }\end{array}$} & A & \multirow{2}{*}{$\begin{array}{c}34^{\circ} 16^{\prime} 48.54^{\prime \prime S} \\
54^{\circ} 0^{\prime} 13.22^{\prime \prime O}\end{array}$} & $\begin{array}{c}2730 \pm 60 \\
{[897 \mathrm{BC}: 804 \mathrm{BC}]}\end{array}$ & $\begin{array}{c}\text { Capdepont et al. } \\
\text { (2002) }\end{array}$ & 1 \\
\hline & & & B & & $\begin{array}{c}2760 \pm 60 \\
{[915 \mathrm{BC}: 810 \mathrm{BC}]}\end{array}$ & $\begin{array}{c}\text { Capdepont et al. } \\
\text { (2002) }\end{array}$ & 2 \\
\hline & & \multirow{2}{*}{$\begin{array}{c}\text { Guardia del } \\
\text { Monte }\end{array}$} & A & \multirow{2}{*}{$\begin{array}{l}34^{\circ} 17^{\prime} 40.07^{\prime \prime S} \\
53^{\circ} 51^{\prime} 37.36^{\prime \prime O}\end{array}$} & $\begin{array}{c}2330 \pm 50 \\
{[404 \mathrm{BC}: 354 \mathrm{BC}]} \\
1260 \pm 60 \\
{[690 \mathrm{AD}: 888 \mathrm{AD}]}\end{array}$ & $\begin{array}{c}\text { Capdepont et al. } \\
\text { (2005), Del Puerto } \\
\text { et al. (2016) }\end{array}$ & 3 \\
\hline & & & B & & $\begin{array}{c}1165 \pm 50 \\
\text { [889AD:986AD] }\end{array}$ & \begin{tabular}{|c|} 
Capdepont et al. \\
(2005), Del Puerto \\
et al. (2016)
\end{tabular} & 4 \\
\hline & $\begin{array}{c}\text { Planicie aluvial } \\
\text { del Río San Luis }\end{array}$ & $\begin{array}{c}\text { Puntas de } \\
\text { San Luis } \\
\text { (PSL) }\end{array}$ & 2 & $\begin{array}{l}33^{\circ} 38^{\prime} 40.04^{\prime \prime} \mathrm{S} \\
53^{\circ} 51^{\prime} 52.0^{\prime \prime} \mathrm{O}\end{array}$ & $\begin{array}{c}4100 \pm 90 \\
{[2852 \mathrm{BC}: 2475 \mathrm{BC}]} \\
2680 \pm 130 \\
{[972 \mathrm{BC}: 544 \mathrm{BC}]}\end{array}$ & $\begin{array}{l}\text { Inda y Del Puerto } \\
\text { (2007) }\end{array}$ & 5 \\
\hline & \multirow{2}{*}{$\begin{array}{l}\text { Sierra de San } \\
\quad \text { Miguel }\end{array}$} & Isla larga & CG14E01 & $\begin{array}{c}33^{\circ} 41^{\prime} 46.19^{\prime \prime S} \\
53^{\circ} 41^{\prime} 51.8^{\prime \prime O}\end{array}$ & $\begin{array}{c}3660 \pm 120 \\
{[2191 \mathrm{BC}: 1777 \mathrm{BC}]} \\
1190 \pm 80 \\
{[778 \mathrm{AD}: 988 \mathrm{AD}]}\end{array}$ & Iriarte (2003) & 6 \\
\hline & & $\begin{array}{l}\text { Bañado de } \\
\text { San Miguel }\end{array}$ & CH2D01-B & $\begin{array}{l}33^{\circ} 43^{\prime} 53.24^{\prime \prime} \mathrm{S} \\
53^{\circ} 36^{\prime} 19.96^{\prime \prime} \mathrm{O}\end{array}$ & $\begin{array}{c}2530 \pm 60 \\
{[767 \mathrm{BC}: 540 \mathrm{BC}]} \\
1090 \pm 70 \\
{[893 \mathrm{AD}: 1127 \mathrm{AD}]}\end{array}$ & $\begin{array}{c}\text { Del Puerto (2015), } \\
\text { Del Puerto et al. } \\
\text { (2016) }\end{array}$ & 9 \\
\hline & \multirow[t]{2}{*}{$\begin{array}{l}\text { Sierra de los } \\
\quad \text { Ajos }\end{array}$} & Los Ajos & Gama & $\begin{array}{c}33^{\circ} 41^{\prime} 95.5^{\prime \prime} \mathrm{S} \\
53^{\circ} 57^{\prime} 42.5^{\prime \prime O}\end{array}$ & $\begin{array}{c}4190 \pm 40 \\
{[2869 \mathrm{BC}: 2637 \mathrm{BC}]} \\
3460 \pm 100 \\
{[1879 \mathrm{BC}: 1618 \mathrm{BC}]}\end{array}$ & Iriarte (2003) & 10 \\
\hline & & \begin{tabular}{|c|} 
Bañado de \\
India Muerta
\end{tabular} & EMA & $\begin{array}{c}33^{\circ} 47^{\prime} 11.1^{\prime \prime S} \\
54^{\circ} 00^{\prime} 56.2^{\prime \prime} \mathrm{O} \\
\end{array}$ & $\mathrm{s} / \mathrm{d}$ & Iriarte (2001) & 8 \\
\hline & Laguna Negra & $\begin{array}{c}\text { Rincón de los } \\
\text { Indios }\end{array}$ & III & $\begin{array}{l}33^{\circ} 53^{\prime} 52.95 " \mathrm{~S} \\
53^{\circ} 42^{\prime} 50.87^{\prime \prime O}\end{array}$ & $\begin{array}{c}2700 \pm 150 \\
{[1007 \mathrm{BC}: 545 \mathrm{BC}]} \\
770 \pm 85 \\
{[1220 \mathrm{AD}: 1383 \mathrm{AD}]}\end{array}$ & $\begin{array}{c}\text { Iriarte (2001), } \\
\text { Gianotti y López } \\
\text { (2009) }\end{array}$ & 7 \\
\hline \multirow[t]{2}{*}{\begin{tabular}{|l} 
Cuenca del Río \\
Tacuarembó \\
(noroeste de \\
Uruguay)
\end{tabular}} & Arroyo Yaguarí & Lemos & YALE 27 & $\begin{array}{l}31^{\circ} 56^{\prime} 47.23 " \mathrm{~S} \\
55^{\circ} 20^{\prime} 26.66^{\prime \prime} \mathrm{O}\end{array}$ & $\begin{array}{c}3250 \pm 40 \\
{[1517 \mathrm{BC}: 1429 \mathrm{BC}]} \\
3060 \pm 45 \\
{[1382 \mathrm{BC}: 1134 \mathrm{BC}]}\end{array}$ & $\begin{array}{c}\text { Del Puerto y Inda } \\
\text { (2005), } \\
\text { Gianotti (2005) }\end{array}$ & 11 \\
\hline & $\begin{array}{c}\text { Arroyo } \\
\text { Caraguata }\end{array}$ & Pago Lindo & MU090226Q10 & $\begin{array}{l}32^{\circ} 14^{\prime} 6.23 " \mathrm{~S} \\
55^{\circ} 8^{\prime} 38.32^{\prime \prime O}\end{array}$ & $\begin{array}{c}2894 \pm 35 \\
{[1074 \mathrm{BC}: 933 \mathrm{BC}]}\end{array}$ & $\begin{array}{l}\text { Del Puerto et al. } \\
\text { (2016) }\end{array}$ & 12 \\
\hline \multirow{7}{*}{$\begin{array}{l}\text { Delta del Río } \\
\text { Paraná }\end{array}$} & \multirow{3}{*}{ Delta Superior } & Los Cardos & Cerro los Cardos & $\begin{array}{l}32^{\circ} 28^{\prime} 20.7^{\prime \prime} \mathrm{S} \\
60^{\circ} 27^{\prime} 22.7^{\prime \prime} \mathrm{O}\end{array}$ & $\begin{array}{c}906 \pm 38 \\
{[1153 \mathrm{AD}: 1221]}\end{array}$ & $\begin{array}{c}\text { Bonomo et al. (2011, } \\
\text { 2017) }\end{array}$ & 13 \\
\hline & & \begin{tabular}{|c|} 
Cerros de la \\
Pajas \\
Blancas \\
\end{tabular} & 1 & $\begin{array}{l}32^{\circ} 27^{\prime} 52.3^{\prime \prime} \mathrm{S} \\
60^{\circ} 39^{\prime} 37.3^{\prime \prime} \mathrm{O}\end{array}$ & $\begin{array}{c}650 \pm 70 \\
{[1302 \mathrm{AD}: 1402 \mathrm{AD}]}\end{array}$ & $\begin{array}{c}\text { Bonomo et al. (2011, } \\
\text { 2017) }\end{array}$ & 14 \\
\hline & & \begin{tabular}{|c|}
$\begin{array}{c}\text { Cerros de la } \\
\text { Pajas } \\
\text { Blancas }\end{array}$ \\
\end{tabular} & 2 & $\begin{array}{l}32^{\circ} 27^{\prime} 52.33^{\prime \prime} \mathrm{S} \\
60^{\circ} 39^{\prime} 37,3, \prime \mathrm{O}\end{array}$ & $\mathrm{s} / \mathrm{d}$ & \begin{tabular}{|c|} 
Bonomo et al. (2011, \\
2017)
\end{tabular} & 15 \\
\hline & & $\begin{array}{l}\text { Tapera } \\
\text { Vázquez }\end{array}$ & $\begin{array}{l}\text { Cerro Tapera } \\
\text { Vázquez (CTV) }\end{array}$ & $\begin{array}{l}32^{\circ} 8^{\prime} 16.6^{\prime \prime} \mathrm{S} \\
60^{\circ} 38^{\prime} 7.5^{\prime}, \mathrm{O}\end{array}$ & $\begin{array}{c}650 \pm 60 \\
{[1422 \mathrm{AD}: 1606 \mathrm{AD}]} \\
520 \pm 60 \\
{[1399 \mathrm{AD}: 1460 \mathrm{AD}]}\end{array}$ & \begin{tabular}{|c|} 
Bonomo et al. (2011, \\
2012, 2017), \\
Colobig et al. (2015)
\end{tabular} & 16 \\
\hline & & $\begin{array}{c}\text { Los Tres } \\
\text { Cerros (LTC) }\end{array}$ & LTC1 & $\begin{array}{l}32^{\circ} 51^{\prime} 17.5^{\prime \prime} \mathrm{S} \\
60^{\circ} 33^{\prime} 37.6^{\prime \prime} \mathrm{O}\end{array}$ & $\begin{array}{c}1030 \pm 50 \\
{[1015 \mathrm{AD}: 1146 \mathrm{AD}]} \\
560 \pm 80 \\
{[1320 \mathrm{AD}: 1455 \mathrm{AD}]}\end{array}$ & \begin{tabular}{|c|} 
Brea et al. (2013), \\
Castro y Castiñeira \\
$(2018)$, Colobig et al. \\
$(2015)$
\end{tabular} & 17 \\
\hline & & $\begin{array}{c}\text { Cerro Lote } \\
11\end{array}$ & Cerro Lote 11 & $\begin{array}{l}32^{\circ} 55^{\prime} 66,3^{\prime}{ }^{\prime} \mathrm{S} \\
60^{\circ} 09^{\prime} 80,6{ }^{\prime} \mathrm{O}\end{array}$ & $\begin{array}{c}490 \pm 60 \\
{[1409 \mathrm{AD}: 1492 \mathrm{AD}]}\end{array}$ & \begin{tabular}{|} 
Bonomo et al. (2011, \\
2017)
\end{tabular} & 18 \\
\hline & Delta Inferior & Brazo Largo & Túmulo 1 & $\begin{array}{c}33^{\circ} 48^{\prime} 39,76^{\prime \prime} \mathrm{S} \\
58^{\circ} 33^{\prime} 35.0^{\prime \prime} \mathrm{O}\end{array}$ & $\begin{array}{c}656 \pm 42 \\
{[1311 \mathrm{AD}: 1396 \mathrm{AD}]}\end{array}$ & $\mid \begin{array}{c}\text { Bonomo et al. (2011, } \\
\text { 2017) }\end{array}$ & 19 \\
\hline $\begin{array}{l}\text { Bajo río } \\
\text { Uruguay } \\
\text { (margen } \\
\text { occidental) }\end{array}$ & Gualeguaychú & $\begin{array}{l}\text { Cerros de } \\
\text { Boaris }\end{array}$ & CDB3 & $\begin{array}{c}33^{\circ} 4^{\prime} 6.96^{\prime \prime} \mathrm{S} \\
58^{\circ} 26^{\prime} 16.04^{\prime \prime O}\end{array}$ & $\begin{array}{c}1440 \pm 50 \\
\text { 601AD:675AD] } \\
\text { Moderno }\end{array}$ & $\begin{array}{c}\text { Castro (2017), } \\
\text { Castro y Castiñeira } \\
\text { (2017) }\end{array}$ & 20 \\
\hline
\end{tabular}




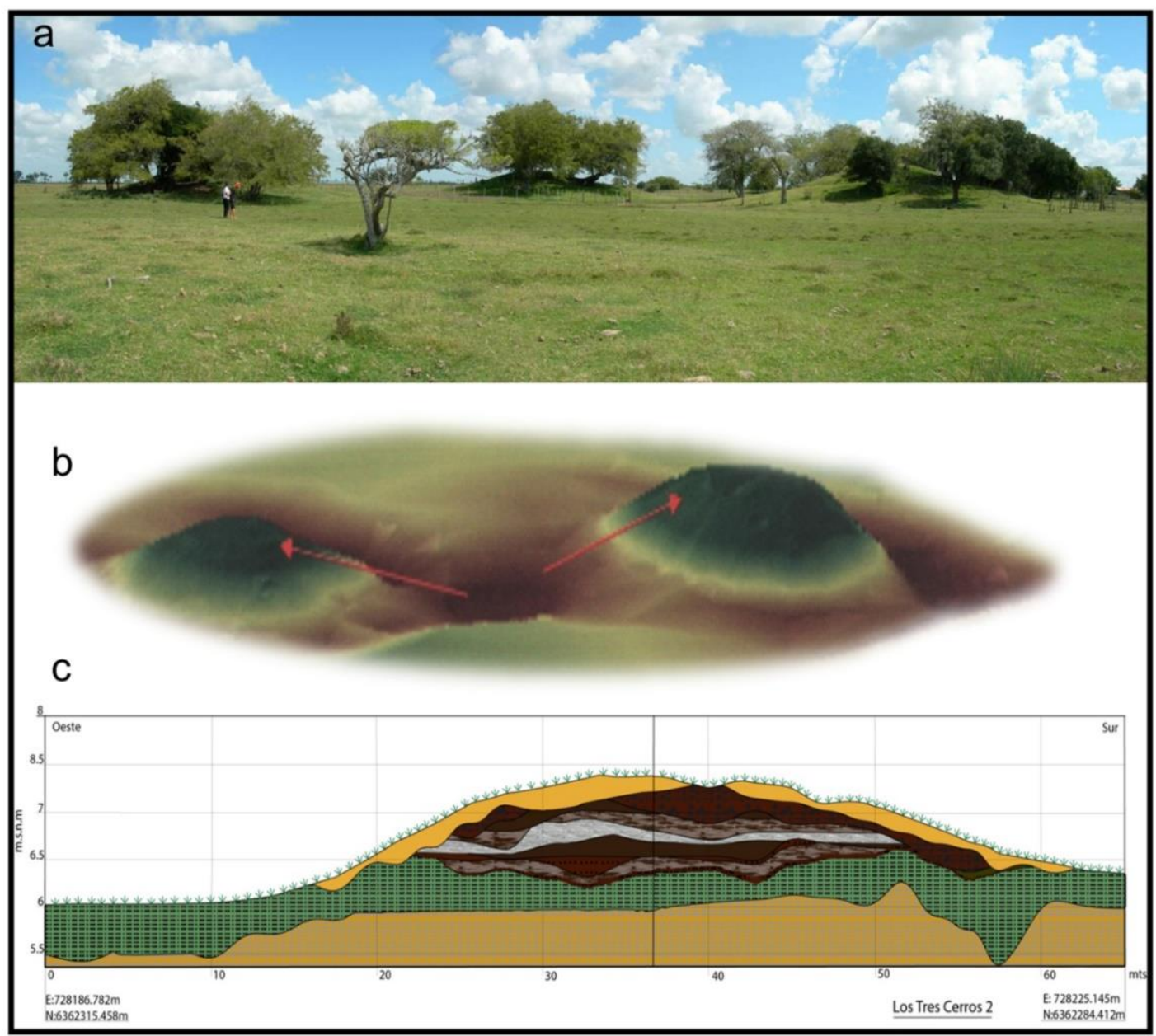

Figura 2. Los cerritos. a: Conjunto de estructuras del sitio PSL de la región de humedales del este de Uruguay (foto gentileza de CAPDEPONT, I. b: Reconstrucción planialtimétrica de localidad arqueológica con inferencia del área de aprovisionamiento de sedimentos utilizados para las construcciones en el Delta Superior del río Paraná (de referencia BONOMO, 2012). c:Reconstrucción de la secuencia sedimentaria del cerrito LTC2 de la localidad LTC del Delta Superior del río Paraná. Los depósitos basales corresponden al sistema natural de depositación aluvial. Los depósitos suparayacentes corresponden al sistema de depositación antrópica. Por último, cubierta edáfica actual (de referencia CASTIÑEIRA, et.al., 2017b).

En el extremo occidental de la Sierra de San Miguel y bajo el dominio del bosque serrano (GAUTREAU y LEZAMA, 2009; SAYAGUÉS et al., 2000) se emplaza la localidad arqueológica Isla Larga (Figura 1). De esta localidad se destaca la presencia de un cerrito (Id.6 en Tabla 1) (CABRERA et al., 2000), con cronologías de 3660 años ${ }^{14}$ CA.P. y 1100 años ${ }^{14}$ CA.P. (CABRERA, 2013; IRIARTE, 2003, Tabla 1). De este sitio, incorporamos los registros arqueobotánicos proporcionados en Iriarte (2003) (Tabla 2).

En la planicie baja de la Sierra de San Miguel, donde se desarrolla el Bañado de San Miguel, se emplaza la localidad CH2D01 (Tabla 1). Esta localidad, cuenta con la presencia de dos cerritos y microrelieves de origen antrópico (CABRERA y CURBELO, 1990). Para este trabajo integramos los registros arqueobotáncios obtenidos de la cara interna y externa de los contenedores cerámicos recuperados en el interior del cerrito $\mathrm{CH} 2 \mathrm{DO} 1$ - B (Id. 4 Tabla1) y los procedentes de la matriz sedimentaria del mismo. Ambos registros, fueron informados en del Puerto et al. (2016a). Las cronologías obtenidas para este sitio se ubican en torno a los 2500 - 1000 años ${ }^{14}$ CA.P. (Tabla 1). 
Tabla 2. Trabajos de referencia para la base de datos, discriminando procedencia de los registros, contexto de recuperación y análisis para la identificación de las taxa arquebotánicas. Referencias: unidades de análisis son los sitios con Id. de Tabla 1.

\begin{tabular}{cccc}
\hline $\begin{array}{c}\text { Datos paleobotánicos } \\
\text { tomados de: }\end{array}$ & Unidades de análisis & $\begin{array}{c}\text { Procedencia de los registros } \\
\text { arqueobotánicos }\end{array}$ & Análisis arqueobotánicos \\
\hline Bonomo et al. (2017) & $(13)(14)(15)(19)(16)(17)(18)$ & $\begin{array}{c}\text { Contenedores cerámicos } \\
\text { Cuchara cerámica } \\
\text { Bonomo et al (2012) }\end{array}$ & $\begin{array}{c}\text { Silicofitolitos, almidones } \\
\text { Silicofitolitos, almidones } \\
\text { Silicofitolitos y }\end{array}$ \\
Bonomo et al. (2010) & $(16)$ & Matriz sedimentaria, & paleoantracológicos \\
sedimentos & paleoantracológicos \\
Brea et al. (2013) & $(16)$ & Sedimentos, Matriz & Silicofitolitos y \\
& $(17)$ & sedimentaria & paleoantracológicos \\
Castro (2017) & $(20)$ & Piedras de moler, sedimentos & Silicofitolitos \\
Capdepont et al. (2002) & $(1)(2)$ & Sedimentos & Silicofitolitos \\
Capdepont et al. (2005) & $(3)(4)$ & Contenedores cerámicos, & Paleocarpológicos \\
Colobig et al. (2015) & $(17)$ & sedimentos & Silicofitolitos \\
Del Puerto et al. (2016a) & $(9)(1)(2)(3)(4)$ & Sedimentos & Silicofitolitos \\
Del Puerto et al. (2016b) & $(12)$ & matriz sedimentaria & Antracológicos \\
Inda y Del Puerto (2007) & $(5)$ & Sedimentos, piedras de moler & Silicofitolitos y almidones \\
Iriarte (2003) & $(10)$ & Sedimentos & Silicofitolitos y almidones \\
Iriarte (2001) & $(7)(6)(8)$ & Sedimentos & Silicofitolitos \\
Sánchez et al. (2013) & $(17)$ & Sedimentos & Silicofitolitos \\
Del Puerto y Inda (2005) & $(11)$ & &
\end{tabular}

A casi $40 \mathrm{Km}$ al suroeste de la Sierra de San Miguel, se desarrolla otro complejo de sierras conocidas como Sierra de Los Ajos. En la planicie asociada a la unidad colinas y lomadas de este sistema serrano, se emplaza una muy alta concentración de cerritos. Las cronologías obtenidas para la localidad Los Ajos (Tabla 1), indican que los cerritos del área, fueron elevados entre los 4500 y 2000 años ${ }^{14}$ C A.P. (IRIARTE, 2007b). Los datos procesados en este trabajo corresponden a los sitios Id. 10 e Id.8 (Tabla 1) informados por Iriarte $(2001,2003)$. En estos trabajos, se reportan taxa arqueobotánicas reconocida mediante el análisis de los fitolitos incluidos en los sedimentos del sitio Id. 10 y de las reconocidas mediante el estudio de los residuos de almidón, adheridos a las paredes de las piedras de moler, recuperadas del mismo sitio. También, incluimos la identificación del biosílice albergado en los sedimentos del sitio Id. 8 (Tabla 2).

\section{Localidades arqueológicas en la cuenca del río Tacuarembó}

La cuenca del río Tacuarembó abarca los territorios comprendidos entre los $30^{\circ} 56^{\prime} \mathrm{S}-55^{\circ} 38^{\prime} \mathrm{O}$ a los $c a .32^{\circ} 28^{\prime} \mathrm{S}-54^{\circ} 20^{\prime} \mathrm{O}$. Su topografía, se caracteriza por ser una penillanura poco ondulada en la que afloran rocas sedimentarias (PANARIO, 1988). La cuenca se caracteriza por ser un hotspot de biodiversidad en el territorio (BRAZEIRO et al., 2008). La flora dominante es la pradera, pero, sobre los márgenes de los cursos de agua, se desarrolla una importante extensión de monte ribereño. Otro paisaje singular en los dominios de la cuenca del Tacuarembó, es el de "Montes de quebradas", cuya vegetación se asemeja a las selvas subtropicales paranaenses (BRUSSA y GRELA, 2007).

La planicie aluvial del río Tacuarembó se recorta con la presencia de tributarios como el arroyo Yaguarí, en este sistema, se desarrollan extensos bañados y lagunas. En las planicies bajas, se destaca una importante concentración de cerritos (CAPDEPONT et al., 2005; GIANOTTI, 2005). De acuerdo a las investigaciones arqueológicas, la construcción de cerritos en la cuenca del río Tacuarembó pudo haber comenzado ca. $\operatorname{los} 3300$ años ${ }^{14} \mathrm{C}$ A.P. (GIANOTTI, 2005; GIANOTTI y BONOMO, 2013). Una de las localidades arqueológicas de referencia, es Lemos (Tabla 1), en la cual, se han registrado 52 cerritos, 11 microrelieves y otras estructuras antrópicas (GIANOTTI et al., 2005). De esta localidad, ingresamos los datos publicados en del Puerto e Inda (2005) para el sitio Id. 11 (Tabla 2).

En la planicie de inundación del Arroyo Caraguata, tributarios al río Tacuarembó, se ubica la localidad arqueológica Pago Lindo (Tabla 1). Esta localidad, presenta también, una alta densidad de cerritos $(n=37)$, exhibiendo una organización espacial compleja con una alta variabilidad morfológica de construcciones (GIANOTTI, 2015). Las cronologías radiocarbónicas obtenidas para la localidad, 
permiten considerar diferentes momentos en la actividad cultural en un lapso de los 3000 años ${ }^{14} \mathrm{C} A P$ a los 600 años ${ }^{14} \mathrm{C}$ AP (GIANOTTI y BONOMO, 2013). Los datos arqueobotánicos analizados en este trabajo corresponden al sitio Id. 12 (Tabla 1, Figura 1) y son tomados de lo publicado en del Puerto et al. (2016) (Tabla 2).

\section{Localidades arqueológicas del Delta del Río Paraná}

El delta del río Paraná conforma la porción inferior de la cuenca del río Paraná (Figura 1). La región emergida del delta (AMATO y SILVA, 2009; CAVALLOTO, 2002) fue definida como un mosaico de humedales por Malvárez (1999). Su morfología actual, se conformó con posterioridad al último hemiciclo desglacial del Holoceno ca. $\operatorname{los} 6000$ años ${ }^{14}$ C A.P. (CAVALLOTTO et al., 2004). Se caracteriza por la presencia de canales de amplios cauces, con albardones bien desarrollados e islas. La dinámica actual del complejo deltaico está dominada por los regímenes hídricos del Pilcomayo, Bermejo, alto Paraná, Uruguay y Gualeguay y mareas e inundaciones producidas por viento sudeste (IRIONDO, 2004). El área deltaica ha sido afectada de manera diferencial a las variaciones del nivel del mar durante el Holoceno, a los regímenes hidrológicos de las cuencas fluviales asociadas y a los fenómenos meteorológicos. Por ello, que es común que sea seccionada en al menos dos porciones (BÓ, 2006): delta superior (en adelante DSRP) y delta inferior (en adelante DIRP). La presencia permanente de grandes cuerpos de agua y el posicionamiento geográfico del área del delta, generan efectos climáticos locales que han permitido la coexistencia de especies típicas de ecorregiones subtropicales húmedas y típicas de ecorregiones templadas. Sin embargo, la geomorfología y la variabilidad en el grado y tiempo de respuesta a los fenómenos hidrometeorológicos, inciden en que la comunidad vegetal dominante en el DSRP sea el bosque fluvial mixto. En tanto que en DIRP, sea dominante la selva en galería o "Monte Blanco" Paranaense (BURKART, 1957; BÓ et al., 2002).

La región deltaica y sus recursos fue atractiva para la colonización humana circa los 2000 años ${ }^{14} \mathrm{C}$ A.P., siendo su patrón de asentamiento característico, la construcción de cerritos y la ocupación de las geoformas elevadas (Ex.: albardones) en respuesta a la alta vulnerabilidad hidrometeorológica (CASTIÑEIRA et al., 2017a). Para este trabajo, reuniremos de la región deltaica los registros arqueobotánicos procedentes de 7 cerritos (Tabla 1, Figura 1).

Una localidad característica de la colonización humana en las islas del DSRP, es Los Tres Cerros (LTC, Figura 1) (POLITIS, et al., 2011; CASTIÑEIRA, et al., 2013, 2014; 2017b). Como lo indica su nombre, son tres los cerritos: LTC1, LTC2 y LTC3 que se alinean NO-SE. LTC1 es la estructura central (Id. 17 en Tabla 1), de mayores dimensiones y la que concentra hasta el momento el mayor número de investigaciones (BASTOURRE 2014; BREA et al., 2013; CASTIÑEIRA et al., 2015; COLOBIG et al., 2015; DI PRADO y CASTRO, 2014; RAMOS VAN RAAP y SCABUZZO, 2018; SCABUZZO et al., 2015; SANCHEZ et al., 2013). Su proceso constructivo es ubicado próximo a los 1200 años ${ }^{14}$ C A.P. (CASTIÑEIRA et al., 2017b) y su secuencia arqueológica alcanza los 500 años ${ }^{14} \mathrm{C}$ A.P. (Tabla 1). Para este trabajo, seleccionamos los análisis antracológicos, carpológicos y fitolíticos de Brea et al. (20013) y Colobig et al. (2015) (Tabla 2).

Otro de los sitios con un cumulo importante de información referente a los cerriteros deltaicos, es la procedente del sitio CTV (Id. 17 en Tabla 1, Figura 1). Se emplaza en la zona de islas incluidas actualmente en el Parque Nacional Pre - Delta (DSRP) y se destaca en la geomorfología de un albardón asociado a un tributario menor del río Paraná (BONOMO et al., 2010, 2011a, 2011b). Las edades obtenidas (vide Tabla 1), ubican su génesis y ocupación en el entorno de los 650 años ${ }^{14} \mathrm{C}$ A.P. (BONOMO et al., 2014). Los datos arqueobotánicos de CTV son proporcionados por los resultados de los análisis antracológicos y de los fitolitos identificados en la matriz sedimentaria (Tabla 2), publicados en Bonomo et al. (2010). Incorporamos, los datos generados por los análisis de fitolitos y almidones recuperado de la superficie interna de una cuchara cerámica procedente del sitio y publicado en Bonomo et al. (2012, 2017).

Del DSRP integramos también, los registros botánicos recuperados de las paredes de los contenedores cerámicos de los sitios: Cerro Los Cardos (Id.13), Cerro de las Pajas Blancas 1 y 2 (Id. 14 y 15, respectivamente) y Cerro Lote 11 (Id.18; Tabla 1). El sitio Cerro los Cardos, se emplaza en un albardón, y su ocupación se ubica próxima a los 900 años ${ }^{14}$ C A.P. (BONOMO et al., 2011b, 2017). Bajo esta modalidad de emplazamiento, contamos con la información procedente de los dos cerritos de la localidad Cerro de las Pajas Blancas (BONOMO et al., 2010), con cronologías que posicionan su ocupación en torno a los 650 años ${ }^{14}$ C A.P. (BONOMO et al., 2011b). Finalmente, el sitio Cerro Lote 11 , cuenta con una cronología que posiciona su ocupación en el entorno de los 500 años ${ }^{14} \mathrm{C}$ A.P. 
(BONOMO et al., 2011b). Para este conjunto de sitios (Id: 13, 14, 15 y 18 seleccionamos los datos arqueobotánicos dados a conocer en Bonomo et al. (2010, 2017; Tabla 2).

En el contexto fitogeográfico del DIRP (MALVÁREZ, 1999), se emplaza el sitio Id. 19 (Figura 1, Tabla 1), nombrado como Túmulo I del Brazo Largo (TORRES, 1911). Restos óseos humanos recuperados de este sitio y albergados en la colección bioarqueológica del Museo de La Plata brindaron una cronología $c a$. los 650 años ${ }^{14} \mathrm{C}$ AP (BONOMO et al., 2011b). Los datos arqueobotánicos integrados a este trabajo fueron comunicados en Bonomo et al. (2017) y se corresponden a la identificación de granos de almidones preservados en contenedores cerámicos (Tabla 2).

\section{Litoral occidental del bajo río Uruguay}

En el litoral occidental del bajo río Uruguay donde se aprecian los cerritos, se desarrollan pantanos, bañados y lagunas permanentes y semipermanentes donde el avenamiento de las aguas es impedido por la escasa pendiente y la delimitación que imponen los albardones y otras geoformas elevadas (IRIONDO y ALTAMIRANO, 1988). Son los bosques xerófilos (CASTRO, 2017), la vegetación característica que se desarrolla sobre los depósitos aluviales que recubren la antigua llanura de mareas (CAVALLOTTO et al., 2004).

En la margen izquierda del río Gualeguaychú (334'6.96"S - 58²6'16.04"O), próxima a la desembocadura en el río Uruguay (Figura 1), se destaca la localidad arqueológica Cerros de Boaris (CDB) (Figura 1). Esta localidad, se caracteriza por presentar tres montículos (CDB1, CDB2 y CDB3) con alturas que varían entre $1,5 \mathrm{~m}$ a $4 \mathrm{~m}$ y diámetros promedios de $50 \mathrm{~m}$ (CASTRO y CASTIÑEIRA, 2017). Las edades radiocarbónicas de los depósitos basales de los cerritos de CDB, son hasta el momento, las más tempranas obtenidas para la modalidad constructiva del nordeste argentino y sus ocupaciones alcanzaron tiempos históricos (CASTRO y CASTIÑEIRA, 2017). Los datos paleobotánicos que son analizados en este trabajo corresponden a los registros arqueobotánicos para el sitio CDB3 (Id 20 en Tabla 1) y dados a conocer en Castro (2017) (Tabla 2).

\section{METODOLOGÍA, EVIDENCIAS Y TÉCNICAS DE ANÁLISIS}

Las evidencias arqueobotánicas analizadas en este trabajo, procedentes de los cerritos, se constituye por carbones y semillas parcialmente carbonizadas que integran el grupo de los registros macrobotánicos que fueron objeto de análisis paleoantracológico y paleocarpológicos (Tabla 2). Otro grupo de análisis, se integra por los registros de fitolitos (microrrestos silíceos de células vegetales) y granos de almidones (productos de la polimerización de la glucosa en los vegetales), agrupados en el conjunto de evidencias microbotánicas (Tabla 2). La afinidad botánica de las macro y micro evidencias han sido dada a conocer, para cada localidad arqueológica, por los autores que se listan en la Tabla 2. Los elementos de la cultura material de donde fueron recuperadas son: diferentes secciones de contenedores cerámicos (vasijas y una cuchara) y piedras de moler como se lista en la Tabla 2 y se ejemplifican en la Figura 3. Arqueológicamente y etnográficamente, los artefactos cerámicos, han sido asociados al almacenamiento y/o procesamiento de recursos vegetales para su consumo alimenticio y/o para su uso medicinal (BONOMO et al., 2011a; CAPDEPONT, 2013; CAPDEPONT y PINTOS, 2006; COLOBIG et al., 2015; DEL PUERTO et al., 2016; LÓPEZ et al., 2014a). En tanto que las piedras de moler (incluye: manos, morteros, rompecocos), son asociadas al procesamiento de los recursos (Ex: vegetales, faunísticos, minerales) mediante molienda (CAPDEPONT et al., 2005; IRIARTE, 2003). La presencia de restos antracológicos (restos leñosos carbonizados) y carpológicos (semillas parcialmente quemadas), en los cerritos, han sido mayormente asociados a la selección de los recursos por sus propiedades combustibles y en menor medida, por propiedades alimenticias y/o medicinal, para la construcción y/o para el acondicionamiento de espacios (BREA et al., 2013; CASTIÑEIRA et al., 2013; INDA y DEL PUERTO, 2007;). Por su parte, los silicofitolitos contenido en las muestras de sedimentos, han sido informantes claves para reconocer, la oferta natural de los recursos vegetales (Ex.: DEL PUERTO, 2011) y para inferir conductas de manejo productivo de estos recursos (IRIARTE et al., 2004, 2007 b; DEL PUERTO, INDA, 2005). En este trabajo, los fitolitos que integran la población sedimentaria (bio-clastos), los referimos como evidencias del manejo antrópico de los recursos botánicos que entraron a las unidades domésticas por el desarrollo de las actividades cotidianas y/o eventuales emprendidas por los cerriteros. 
a

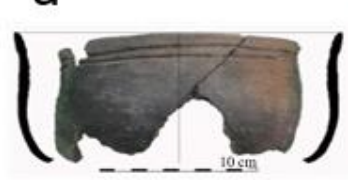

b

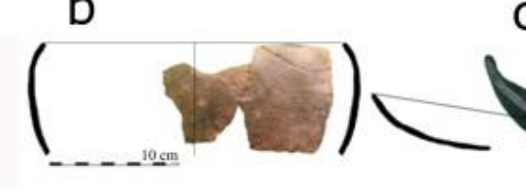

C
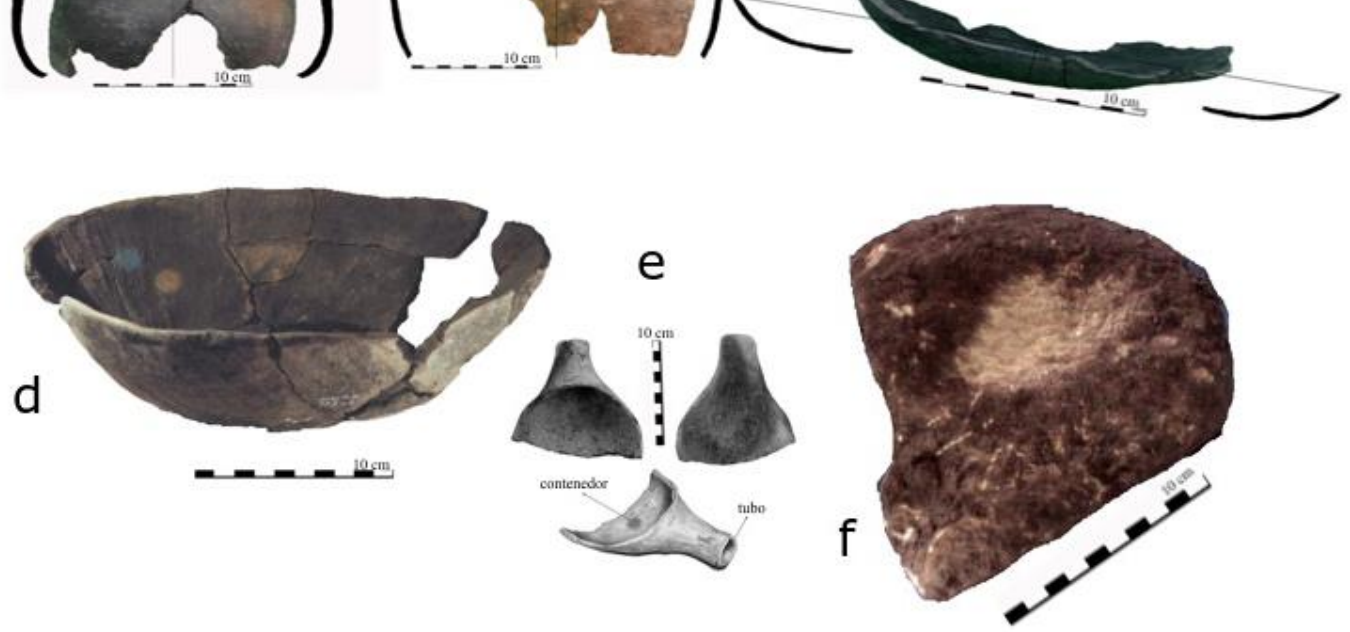

Figura 3. Artefactos culturales. a,b,c: reconstrucción de forma de los contendores cerámicos del cerrito LTC1 (CASTRO, CASTIÑEIRA, 2018). d: contenedor de cerámica del cerrito CH2DO1 (CAPDEPONT, 1996). e: cuchara de cerámica del cerrito CTV (BONOMO,et al. 2012). f: piedra de moler del cerrito GM A (CAPDEPONT, et al., 2005).

Para el tratamiento de los datos, se generó una tabla incorporando las familias arqueobotánicas identificadas en los trabajos citados en Tabla 2. Se cuantifico el número de menciones por familia (Figura 4). Cuando los artículos de referencia presentaban categorías taxonómicas inferiores a nivel de familia (EX.: subfamilia y tribu), se optó por considerar, el nivel de familia. En la Tabla 3, se listan las especies botánicas asociadas a las taxa arqueobotánicas reportadas, diferenciando su adscripción a cerritos emplazados en las áreas continentales o en la zona deltáica del Paraná. En los casos en que los trabajos listados en Tabla 2, no proveyeron una asociación específica, se estableció un criterio de asociación acorde a la información fitogeográfica actual para las especies nativas (vide Tabla 3).Se recurrió para ello, a los datos disponibles en: Barrenche y Zarucki (2017), del Puerto (2011), Paz y Bassagoda (1999) para los HEU y para la cuenca del río Tacuarembó, lo disponible en: Ministerio de Vivienda Ordenamiento Territorial y Medio Ambiente (2018) y Castiñeira, E. (2017). Para el delta del río Paraná - Argentina, los datos proporcionados en Burkart (1957), Kandus et al. (2006), Madanes et al. (2013), Malvárez (1999). Finalmente, para el litoral del río Gualeguaychú - Argentina, la información disponible en Takáts y Toselli (2016). Los nombres científicos de las especies fueron actualizados según la base de datos en The Plant List (2013).

Figura 4. Número de menciones de familia arqueobotánicas reconocidas en los diferentes contextos de hallazgos.

\section{Número de mensiones por familia según contexto}

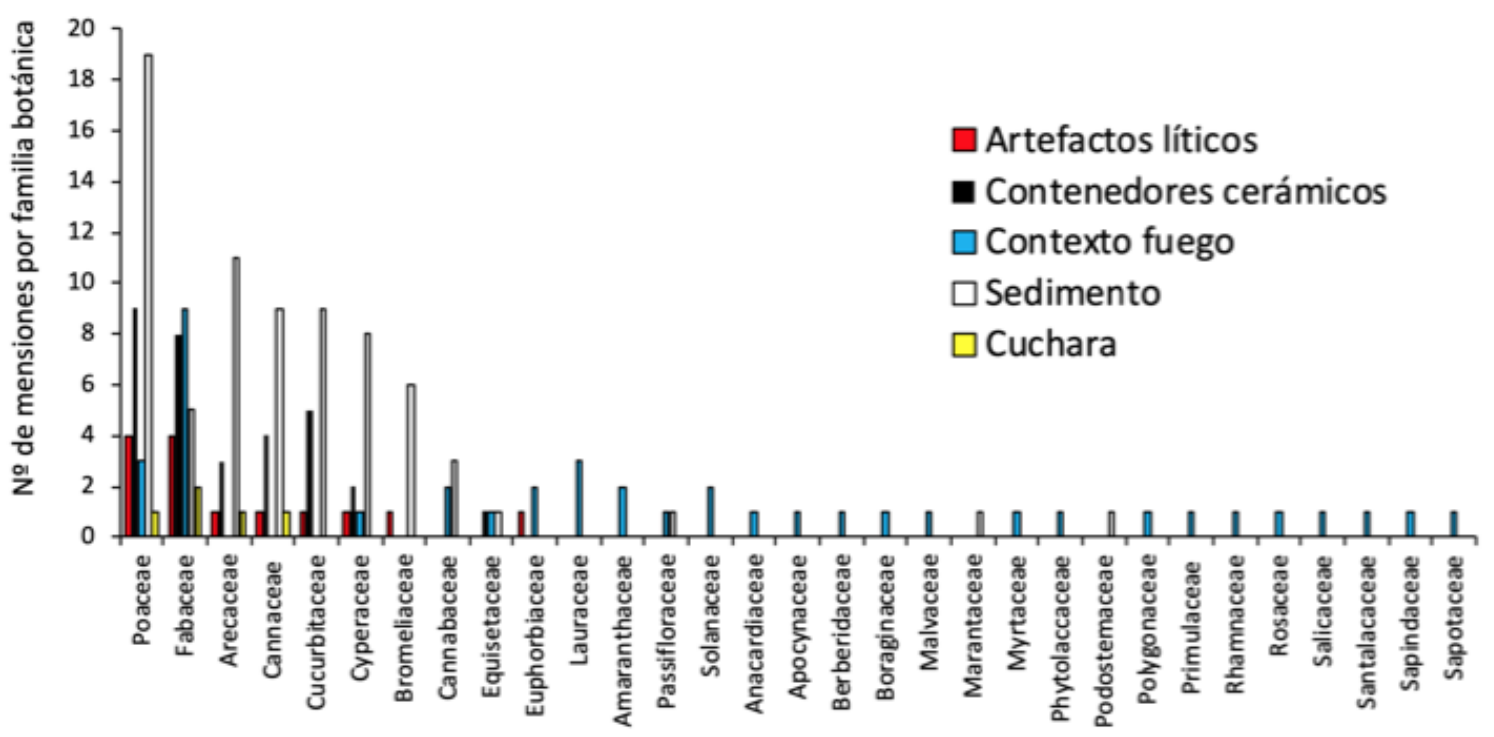


La matriz de análisis se construyó en base binaria de presencia/ausencia de familias arqueobotánicas mencionadas para cada sitio, discriminando tipo de evidencia (micro resto - macro resto), análisis del registro (antracológico, carpológico, fitolítico, almidones) y contexto de procedencia de la evidencia (sedimento, adherido a instrumento cerámico o lítico) (Tabla 4). A la matriz, se le adicionó los usos medicinales asignados en los trabajos arqueobotánicos (listados en Tablas 1 y 2) y los usos medicinales reportados en la bibliografía etnobotánica de referencia (Ex.: ALONSO y DESMARCHELIER, 2015; ALVAREZ, 2019; ARENAS, 2009; FERREIRA et al., 2017; HERNÁNDEZ y ARAMABARRI, 2011; MARTINEZ, 2011; PIRONDO et al., 2018; SCARPA y ROSSO, 2019; y demás trabajos citados en CASTIÑEIRA, 2017). En otra columna, se asignaron a las categorías de dolencias definidas por Castiñeira (2017) como se reporta en Tabla 5. Fueron calculadas las frecuencias.

Con el fin de analizar la asociación entre las familias botánicas identificadas con usos botánicos y los contextos de recuperación de las evidencias (ex. cuchara, mortero, contenedor de cerámica, sedimentos, fuego) realizamos un análisis de correspondencia. Este método permite realizar una representación gráfica incorporando los dos componentes de la matriz (BORCARD et al., 2011). La matriz fue construida con las familias botánicas en las filas y los contextos arqueológicos en las columnas, siendo el contenido de las celdas la presencia de la familia botánica asociada a un contexto citada en al menos una publicación. El análisis de correspondencia fue realizado utilizando la función $c a$ del paquete 'ca' versión 7.0 (NENADIC y GREENACRE, 2007) del programa estadístico R (R CORE TEAM, 2019).

Tabla 3. Lista de familias botánicas reportadas para las unidades de análisis. Referencias: Especies ( $S p$.) asociadas según emplazamiento fitogeográfico (a) o reconocidas por los análisis arqueobotánicos (r), diferenciando si el registro es continental (C) o deltáico (D).

\begin{tabular}{|c|c|c|}
\hline Familias & Spp. asociada(s)/reconocida(s) por estudio arquebotánico (r) & $\begin{array}{c}\text { Registro deltaico/ } \\
\text { continental }\end{array}$ \\
\hline Anacardiaceae & Schinus molle L. (a) & $C$ \\
\hline Apocynaceae & Aspidosperma Mart. \& Zucc. (r) & $C$ \\
\hline Arecaceae & Butia odorata (Barb. Rodr.) Noblick; Butia yatay (Mart.) Becc. (r) & $D, C$ \\
\hline Berberidaceae & Berberis L. (a) & $C$ \\
\hline Boraginaceae & Cordia L. Cordia trichotoma (Vell.) Arráb. Ex. Steud (r) & $D$ \\
\hline Bromeliaceae & Bromelia anticantha Bertol. (a) & $C$ \\
\hline Cannabaceae & Celtis tala Gillies ex Planch (r) & $C$ \\
\hline Cannaceae & Canna glauca L.Canna indica L.(r) & $D, C$ \\
\hline Chenopodiaceae & Chenopodium ambrosioides L. Amaranthus deflexus L. (r) & $D$ \\
\hline Cucurbitaceae & Cucurbita maxima Duchesne Lagenaria Ser. (r) & $D, C$ \\
\hline Cyperaceae & Cyperus L. Cyperus giganteus Vahl (r) & $D, C$ \\
\hline Equisetaceae & Equisetum $\mathrm{L}$. & $D, C$ \\
\hline Euphorbiaceae & Sapium Jacq. Sapium haematospermum Müll. Arg. (r) & $D, C$ \\
\hline Lauraceae & Ocotea Aubl. Nectandra Rol. ex Rottb. (r) & $D, C$ \\
\hline Leguminosae & $\begin{array}{c}\text { Inga urugüensis Hook. \& Arn. Acacia caven Molina } \\
\text { Parapiptadenia rigida (Benth.) Bernan, Prosopis nigra (Griseb.) Hieron. (r) } \\
\text { Phaseolus vulgaris L. Sp.Pl.(r) }\end{array}$ & $D, C$ \\
\hline Malvaceae & Ceiba speciosa (A. St.-Hil.) Ravenna (a) & $C$ \\
\hline Marantaceae & Thalia geniculata L. (a) & $C$ \\
\hline Myrtaceae & Blepharocalyx salicifolius (H.B.K.) O. Berg. & $C$ \\
\hline Passifloraceae & Passiflora L.Sp.Pl. (r) & $D, C$ \\
\hline Phytolaccaceae & Phytolacca dioica L.(r) & $C$ \\
\hline Poaceae & Zea mays L., Oryza latifolia Desv. Guadua Kunth (r) & $D, C$ \\
\hline Podostemaceae & $?$ & $D$ \\
\hline Polygonaceae & Polygonum punctatum Elliott Small (r) & $D$ \\
\hline Primulaceae & Myrsine laetevirens (Mez) Arechav (r) & $D$ \\
\hline Rhamnaceae & Scutia buxifolia Reissek (a) & $C$ \\
\hline Rosaceae & Margyricarpus pinnatus (Lam.) O. Kuntze (a) & $C$ \\
\hline Salicaceae & Salix humboldtiana Willd. (r) & $C$ \\
\hline Santalacaceae & Acanthosyris spinescens (Mart. \& Eichler) Griseb. (a) & $\mathrm{C}$ \\
\hline Sapindaceae & $\begin{array}{c}\text { Allophylus edulis (A. St.-Hil., A. Juss. \& Cambess.) } \\
\text { Hieron. ex Niederl. (a) }\end{array}$ & $C$ \\
\hline Sapotaceae & Pouteria salicifolia (Spreng.) Radlk.(a) & $C$ \\
\hline Solanaceae & Lycium cestroides Schltdl. (a) & $D, C$ \\
\hline
\end{tabular}


Para el desarrollo de análisis comparativos entre las áreas geográficas, agrupamos los registros según su emplazamiento conformando dos grupos. Un grupo que reunió las evidencias procedentes de los cerritos deltaicos (Id. 13 a 19, Tabla 1). Otro grupo, con las procedentes de los cerritos emplazados en las restantes áreas continentales: HEU, cuenca del río Tacuarembó y bajo río Uruguay (cerritos Id: 1 a 12 y 20 en Tabla 1$)$.

Tabla 4. Familias botánicas reportadas por contexto de hallazgo y análisis que permitió su identificación. Referencias: ID: número de identificación de los sitios generado en Tabla 1. Sb = fitolítico. $\mathrm{Ch}=$ antracológico, $\mathrm{C}=$ carpológico, $\mathrm{A}=$ almidón.

\begin{tabular}{|c|c|c|c|}
\hline $\begin{array}{l}\text { ID } \\
\text { sitio }\end{array}$ & Registro & $\begin{array}{l}\text { Contexto de } \\
\text { recuperación }\end{array}$ & Familias botánicas \\
\hline 1 & $\mathrm{Sb}$ & $\begin{array}{l}\text { Contenedor } \\
\text { cerámico }\end{array}$ & Poaceae, Arecaceae, Cannaceae, Cyperaceae, Equisetaceae, Cucurbitaceae, Fabaceae \\
\hline 1 & $\mathrm{Sb}$ & Sedimento & Poaceae, Arecaceae, Bromeliaceae, Cannaceae, Cyperaceae, Cucurbitaceae \\
\hline 2 & $\mathrm{Sb}$ & $\begin{array}{l}\text { Contenedor } \\
\text { cerámico }\end{array}$ & Arecaceae, Cannaceae, Poaceae, Cucurbitaceae \\
\hline 2 & $\mathrm{Sb}$ & Sedimento & Poaceas, Arecaceae, Bromeliaceae, Cannaceae, Cyperaceae, Cucurbitaceae \\
\hline 3 & $\mathrm{Sb}$ & Piedras de moler & Cyperaceae, Arecaceae, Bromeliaceae, Poaceae, Cucurbitaceae \\
\hline 3 & $\mathrm{Sb}$ & Sedimento & $\begin{array}{c}\text { Poaceae, Arecaceae, Bromeliaceae, Cannaceae, Cyperaceae, Cucurbitaceae, Fabaceae, } \\
\text { Cannabaceae }\end{array}$ \\
\hline 4 & $\mathrm{Sb}$ & Sedimento & Poaceae, Arecaceae, Cannaceae, Cyperaceae, Cucurbitaceae \\
\hline 5 & $\mathrm{Ch}$ & Sedimento & $\begin{array}{c}\text { Anacardiaceae, Berberidaceae, Euphobracear, Lauraceae, Fabaceae, Myrtaceae, } \\
\text { Phytolaccaceae, Santalacaceae, Rhamnaceae, Rosaceae, Salicaceae, Sapindaceae, } \\
\text { Sapotaceae, Solanaceae }\end{array}$ \\
\hline 6 & $\mathrm{Sb}$ & Sedimento & Marantaceae, Poaceae, Cannaceae \\
\hline 7 & $\mathrm{Sb}$ & Sedimento & Fabaceae, Poaceae, Cucurbitaceae \\
\hline 8 & $\mathrm{Sb}$ & Sedimento & Cannaceae, Leguminosae \\
\hline 9 & $\mathrm{Sb}$ & Sedimento & $\begin{array}{c}\text { Poaceae, Bambusoideae, Bromeliaceae, Cannaceae, Cyperaceae, Cucurbitaceae, } \\
\text { Fabaceae, Equisetaceae, Arecaceae, Cannabaceae }\end{array}$ \\
\hline 9 & $\mathrm{Sb}$ & $\begin{array}{l}\text { Contenedor } \\
\text { cerámico }\end{array}$ & Poaceae, Bambusoideae, Arecaceae, Cannaceae, Cyperaceae, Cucurbitaceae \\
\hline 10 & A & Piedras de moler & Poaceae, Fabaceae, Cannaceae \\
\hline 10 & $\mathrm{Sb}$ & Sedimento & Poaceae, Cucurbitaceae, Cyperaceae, Arecaceae \\
\hline 11 & $\mathrm{Sb}$ & Sedimento & $\begin{array}{c}\text { Bromeliaceae, Cannanaceae, Cyperaceae, Arecaceae, Poaceae, Cucurbita, } \\
\text { Passifloraceae }\end{array}$ \\
\hline 12 & $\mathrm{Sb}$ & Sedimento & Cyperaceae, Bromeliaceae, Poaceae, Arecaceae, Cannaceae \\
\hline 13 & $\mathrm{Sb}$ & Contenedor & Fabaceae, Poaceae, Cannaceae, Cucurbitaceae \\
\hline 14 & $\mathrm{Sb}$ & $\begin{array}{l}\text { Contenedor } \\
\text { cerámico } \\
\text { Contenedor }\end{array}$ & Fabaceae \\
\hline 15 & $\mathrm{Sb}$ & cerámico & Poaceae \\
\hline 16 & $\mathrm{Sb}$ & Piedras de moler & Fabaceae \\
\hline 16 & $\mathrm{Sb}$ & $\begin{array}{l}\text { Cuchara de } \\
\text { cerámica }\end{array}$ & Poaceae, Fabaceae, Cannaceae, Arecaceae \\
\hline 16 & $\mathrm{Sb}$ & Sedimento & Podostemaceae, Arecaceae \\
\hline 16 & $\mathrm{Ch}$ & Sedimento & Lauraceae, Primulaceae, Fabaceae, Poaceae, Bambusoideae \\
\hline 17 & $\mathrm{Sb}$ & Sedimento & Cucurbitaceae, Poaceae, Arecaceae \\
\hline 17 & $\mathrm{Ch}$ & Sedimento & $\begin{array}{c}\text { Lauraceae, Euphorbiaceae, Fabaceae, Boraginaceae, Equisetaceae, Passifloraceae, } \\
\text { Cyperaceae }\end{array}$ \\
\hline 17 & $\mathrm{C}$ & Sedimento & Solanaceae, Amaranthaceae, Poaceae, Polygonaceae, \\
\hline 18 & $\mathrm{Sb}$ & $\begin{array}{l}\text { Contenedor } \\
\text { cerámico }\end{array}$ & Fabaceae, Poaceae \\
\hline 19 & A & Piedras de moler & Fabaceae, Poaceae, Euphorbiaceae \\
\hline 19 & A & $\begin{array}{l}\text { Contenedor } \\
\text { cerámico }\end{array}$ & Fabaceae, Poaceae \\
\hline 20 & $\mathrm{Ch}$ & Sedimento & Fabaceae, Malvaceae,Cannabaceae, Apocynaceae \\
\hline
\end{tabular}

\section{RESULTADOS}

Los datos analizados nos permitieron identificar una riqueza de 32 familias botánicas (Tabla 5). El 59\% de la variabilidad taxonómica reconocida $(\mathrm{N}=19)$ es aportada exclusivamente por los 
análisis antracológicos y carpológicos reportados en Brea et al. (2013), Castro (2017), Colobig et al. (2015) e Inda y del Puerto (2007).

Las familias botánicas con mayor número de menciones en los trabajos de referencia para las diferentes áreas geográficas y en los distintos contextos de hallazgo, correspondieron a: Poaceae, Fabaceae, Cannaceae, Arecaceae, Cucurbitaceae (Tabla 4, Figura 4). La contribución a esta asociación, proviene principalmente de la identificación de microrestos preservados en los materiales culturales y de las muestras de los sedimentos constituyentes de las estructuras monticulares.

Tabla 5. Categorías de dolencias y usos medicinales asociados (sensu CASTIÑEIRA, 2017).

\begin{tabular}{cc}
\hline Categoría & Uso medicinal \\
\hline Car: cardíaco & Palpitaciones, cardiotónico \\
Die: dientes & Calmar odontalgias \\
Dig: digestivo & Estómago, empacho, refrescante, antiespasmódicos, purgante \\
Do: dolor & Analgésico, otalgias \\
G: gastrointestinal & Estómago, intestino, diarreas, obstrucciones, hemorroides, depurativo \\
Hep: hepático & Hígado, secreción de bilis \\
Her: heridas & Cortes, laceraciones, picaduras de insectos, mordidas de animales, \\
Hu: huesos & Articulaciones, artritis, artrosis \\
Inf: infección & Inflamación, pústulas \\
Inm: inmunológico, & Inmunológico \\
Ner: nervioso, & Insomnio, sedantes \\
Pa: parásitos, & Ectoparásitos y endoparásitos (vermífugo) \\
Pi: Piel & Quemaduras, resequedad, eccemas, vulnerario, erupciones cutáneas \\
Ren: renal & Riñones, diurético \\
Rep: reproductivo & Abortivo, ovarios, disfunciones de órganos sexuales, dismenorrea \\
Res: respiratorio & Antitusivo, expectorante, afecciones en vías respiratorias altas y bajas, insuficiencia \\
pulmonar & Antipiréticas \\
Te: temperatura &
\end{tabular}

En el análisis de correspondencia basado en la presencia/ausencia de familias botánicas por contexto de hallazgo permite establecer que, el 83,8\% de la varianza del sistema (dimensión 1: 62,4\%; dimensión 2: 21,4\%), se describe en las primeras dos dimensiones (Figura 5). La dimensión 1, reporta las familias botánicas (Anacadiaceae, Apocynaceae, Berberidaceae, Boraginaceae, Amaranthaceae, Lauraceae, Malvaceae, Myrtaceae, Phytolaccaceae, Primulaceae, Rhamanaceae, Rosaceae, Salinaceae, Santalaceae, Sapindaceae, Sapotaceae, Solanaceae), que caracterizan en este trabajo al contexto fuego y que fuera consignado a las evidencias macroscópicas que presentan signos de termoalteración: parcial, en el caso de las evidencias carpológicas y total, en el caso de los carbones. Mientras que la dimensión 2, reporta por un lado la contribución de las familias botánicas: Arecaceae, Cannaceae, Fabaceae, Poaceae, para la asociación de los contextos artefactuales (cuchara, piedras de moler, contenedores cerámicos) y, por otro lado, a las familias Ulmacae, Passifloraceae, Cannabacea, Marantaceae, Podostemaceae, que caracterizan la composición vegetal de los contextos sedimentarios.

En la Figura 6 se describe la riqueza taxonómica aportada por los contextos de recuperación de las evidencias arqueobotánicas analizadas (piedras de moler, contenedores cerámicos, cuchara, fuego y sedimento), diferenciando las regiones geográficas de procedencia: deltaico, continentales. Se detectan diferencias marginalmente significativas en la riqueza aportada por los contextos de hallazgos de los cerritos deltaicos, respecto de los contextos procedentes de los cerritos emplazados en continente $(\mathrm{Chi}-2=8,93 ; \mathrm{gl}=4 ; \mathrm{p}$-valor $=0,063)$. En los contenedores cerámicos y morteros procedentes de las áreas continentales, los cerriteros, procesaron y/o almacenaron una mayor variedad de recursos botánicos que los del delta del Paraná. En tanto que en los contextos "fuego" de ambas áreas geográficas, se aprecia una riqueza mayor de taxa arqueobotánicas representadas, en relación a los artefactos (Figura 6).

Respecto a los resultados tendientes a aportar al reconocimiento de una farmacopea nativa, el $84 \%$ del total de las familias botánicas que conforman la base de datos analizada, están asociadas a usos medicinales cuyas propiedades terapéuticas son destacadas en la literatura etnobotánica de referencia para la SUCURPLA (Tabla 6). Los usos más conspicuos, estarían relacionados a cubrir 
necesidades terapéuticas causadas por afecciones infecciosas, gastrointestinales, heridas y respiratorias (Figura 7).

Figura 5. Análisis de correspondencia. Se grafican las familias botánicas $(\mathbf{)}$ y los contextos de procedencia de las evidencias ( $\mathbf{\Delta})$. El color del símbolo (no su tamaño) esta en relación con la intensidad en la contribución de cada punto en el análisis.

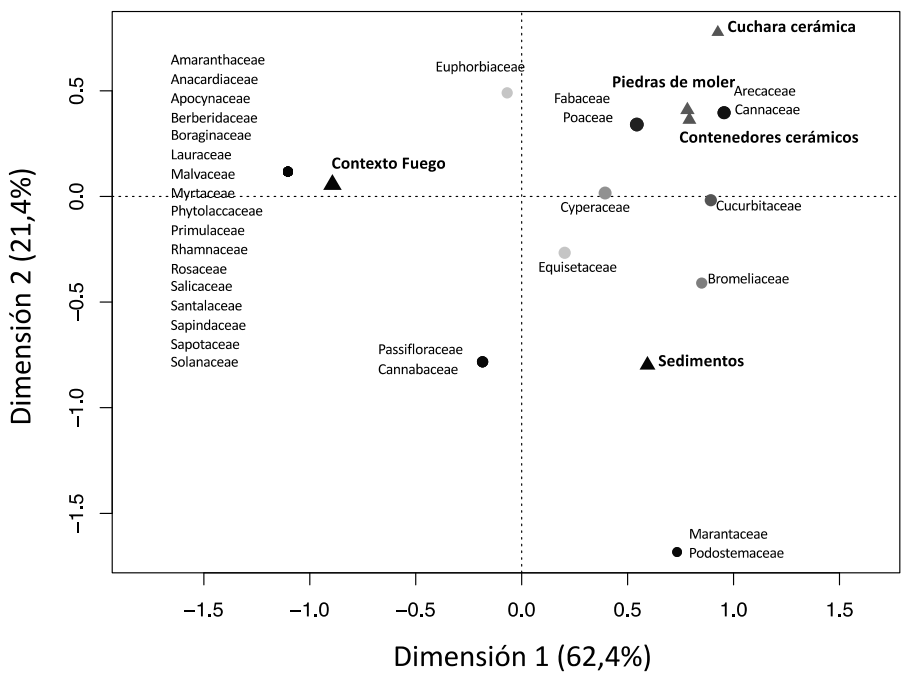

Diferencias significativas también fueron constatadas en la frecuencia de los usos terapéutico de acuerdo a la variabilidad taxonómica de los registros procedentes de los sitios emplazados en el área deltaica del río Paraná vs. los procedentes de las restantes áreas continentales consideradas (Figura 7 b y c). La asociación de los principales usos medicinales manifestado por los registros deltaicos se agrupó de la manera siguiente: Infecciones + Gastrointestinales + (Dolores, Heridas, Parásitos, Renales $)+($ Cardiaco, Reproductivo + Respiratorio $)+$ Nervioso. En tanto, la asociación de los principales usos medicinales de los registros agrupados en la categoría continental fue: Gastrointestinales + (Heridas, Infecciones) + Respiratorias + (Cardiaco + Dolores, Nervioso, Renales, Respiratorios) + (Huesos, Parásitos, Temperatura).

Tabla 6. Familias arqueobotánicas reconocidas en los registros estudiados, especies asignadas y usos medicinales asociados. Referencias: G: gastrointestinal, Her: heridas, Hu: huesos, Res: respiratorio, Do: dolor, Inm: inmunológico, Car: cardiaco, Pa: parásitos, Rep: reproductivo, Inf: infecciones, Ner: nervioso, Pi: Piel, Te: temperatura, Dig: digestivo, Ren: renal, Die: dientes, Hep: hepático.

\begin{tabular}{|c|c|c|}
\hline Familia & Especies & Usos medicinales \\
\hline Anacardiaceae & Schinus molle L. & G, Her, Hu, Res \\
\hline Apocynaceae & Aspidosperma Mart. \& Zucc. & Do, G, Her, Inm, Res \\
\hline Arecaceae & $\begin{array}{l}\text { Butia odorata (Barb. Rodr.) Noblick; Butia yatay (Mart.) Becc.; } \\
\text { Syagrus romanzoffiana (Cham.) Glassman }\end{array}$ & Car, Pa, Rep \\
\hline Berberidaceae & Berberis sp. L. & Hu, Her, Inf, Inm, Ner, Pi, Resp, Te \\
\hline Boraginaceae & Cordia sp. L.; Cordia trichotoma (Vell.) Arráb. ex Steud.) & Dig, Her, Resp, Te \\
\hline Cannabaceae & Celtis tala Gillies ex Planch & Dig, Inf, Pa, Resp \\
\hline Cannaceae & Canna glauca $\mathrm{L} . ;$ Canna indica $\mathrm{L}$. & Do, Hu, Inf, Ren, Rep \\
\hline Amaranthaceae & $\begin{array}{l}\text { Dysphania ambrosioides (L.) Mosyakin \& Clemants; Amaranthus } \\
\text { deflexus L. }\end{array}$ & Pa, Ren \\
\hline Cucurbitaceae & Cucurbita maxima Duchesne; Lagenaria sp. Ser. & $\mathrm{Pa}$ \\
\hline Cyperaceae & Cyperus sp. L.; Cyperus giganteus Vahl & Car, Dig, Her, Inf, Rep \\
\hline Equisetaceae & Equisetum sp. L. & Car, Dig, Her, Inf, Ren, Rep, \\
\hline Euphorbiaceae & Sapium sp. Jacq.; Sapium haematospermum Müll. Arg. & Die, Dig, Her, \\
\hline Lauraceae & Ocotea sp. Aubl.; Nectandra sp. Rol. ex Rottb. & Dig, Inf \\
\hline Fabaceae & $\begin{array}{l}\text { Inga uruguensis Hook. \& Arn.; Acacia caven Molina; } \\
\text { Parapiptadenia rigida (Benth.) Brenan; Prosopis nigra (Griseb.) } \\
\text { Hieron. Phaseolus vulgaris L. }\end{array}$ & Car, Inm, Ner, Res \\
\hline Malvaceae & Ceiba speciosa (A. St.-Hil.) Ravenna & Do \\
\hline Myrtaceae & Blepharocalyx salicifolius (H.B.K.) O. Berg. & Dig, Hep, Res \\
\hline Passifloraceae & Passiflora sp. L. & Ner, Par, Ren \\
\hline Phytolaccaceae & Phytolacca dioica $\mathrm{L}$. & Dig, Resp \\
\hline Poaceae & Zea mays L.; Oryza latifolia Desv. Guadua Kunth & Inf, Ner, Ren \\
\hline
\end{tabular}




\begin{tabular}{clc}
\hline Familia & \multicolumn{1}{c}{ Especies } & Usos medicinales \\
\hline Polygonaceae & Polygonum punctatum Elliott & Dig, Inf, \\
Primulaceae & Myrsine laetevirens (Mez) Arechav & Die \\
Rosaceae & Margyricarpus pinnatus (Lam.) O. Kuntze. & Ren, Rep, Temp \\
Salicaceae & Salix humboldtiana Willd. & Dig, Dol, Hue, Ner \\
Santalacaceae & Acanthosyris spinescens (Mart. \& Eichler) Griseb. & Dig, Her, Tem \\
Sapindaceae & \multicolumn{1}{c}{ Allophylus edulis (A. St.-Hil., A. Juss. \& Cambess.) } & Dig, Her, Tem \\
& Hieron. ex Niederl. & Her \\
Sapotaceae & Pouteria salicifolia (Spreng.) Radlk. & Inf \\
Solanaceae & Lycium cestroides Schltdl. & \\
\hline
\end{tabular}

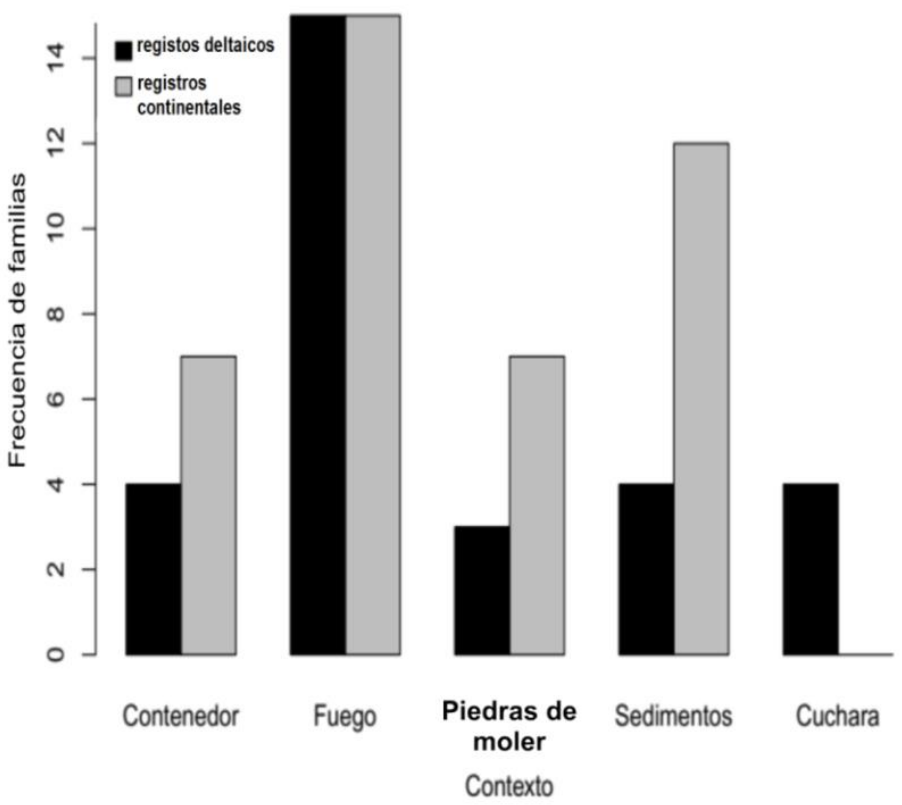

Figura 6. Frecuencia de familias arqueobotánicas reconocidas en los diferentes contextos de hallazgo diferenciando las áreas de emplazamiento de las unidades de análisis.

Se aprecia una diferencia marginalmente significativa entre áreas $($ Chi-2 $=8.93 ; \mathrm{gl}=4$; $\mathrm{p}$-valor $=$ $0,063)$.

\section{DISCUSIÓN}

En diferentes trabajos arqueobotánicos y etnobotánicos se reconoce que, el uso medicinal de los recursos botánicos, supera al alimenticio (vide: listado de usos en DEL PUERTO, 2011; frecuencias de uso en SCARPA y ANACONATANI, 20017; SCARPA y ROSSO, 2014) y a otras posibles utilidades implementadas por los actores sociales que vivieron o viven en contacto estrecho con la naturaleza, tales como: indígenas, campesinos, pobladores y trabajadores rurales (al respecto: ARENAS, 2009; TABAKIAN, 2019). En razón de ello, y dado que el $84 \%$ de las taxa arqueobotánicas listadas en este trabajo se asocian con plantas medicinales, consideramos pertinente otorgarle protagonismo al potencial uso terapéutico, que, para el cuidado o mantenimiento de la salud, pudieron recurrir los cerritos de la SUCURPLA.

Los estudios antracológicos y carpológicos fueron los registros con mayor aporte al reconocimiento de la variabilidad de los recursos botánicos que pudieron participar en las estrategias de vida de los constructores y ocupantes de los cerritos. Estos registros han sido clave para inferir estrategias relacionadas a la alimentación, construcción y acondicionamiento de espacios, de herramientas, generación y mantenimiento de fuegos (BONOMO et al., 2011a; BREA et al., 2013; CASTIÑEIRA et al., 2013; COLOBIG et al., 2015; INDA y DEL PUERTO, 2007). 

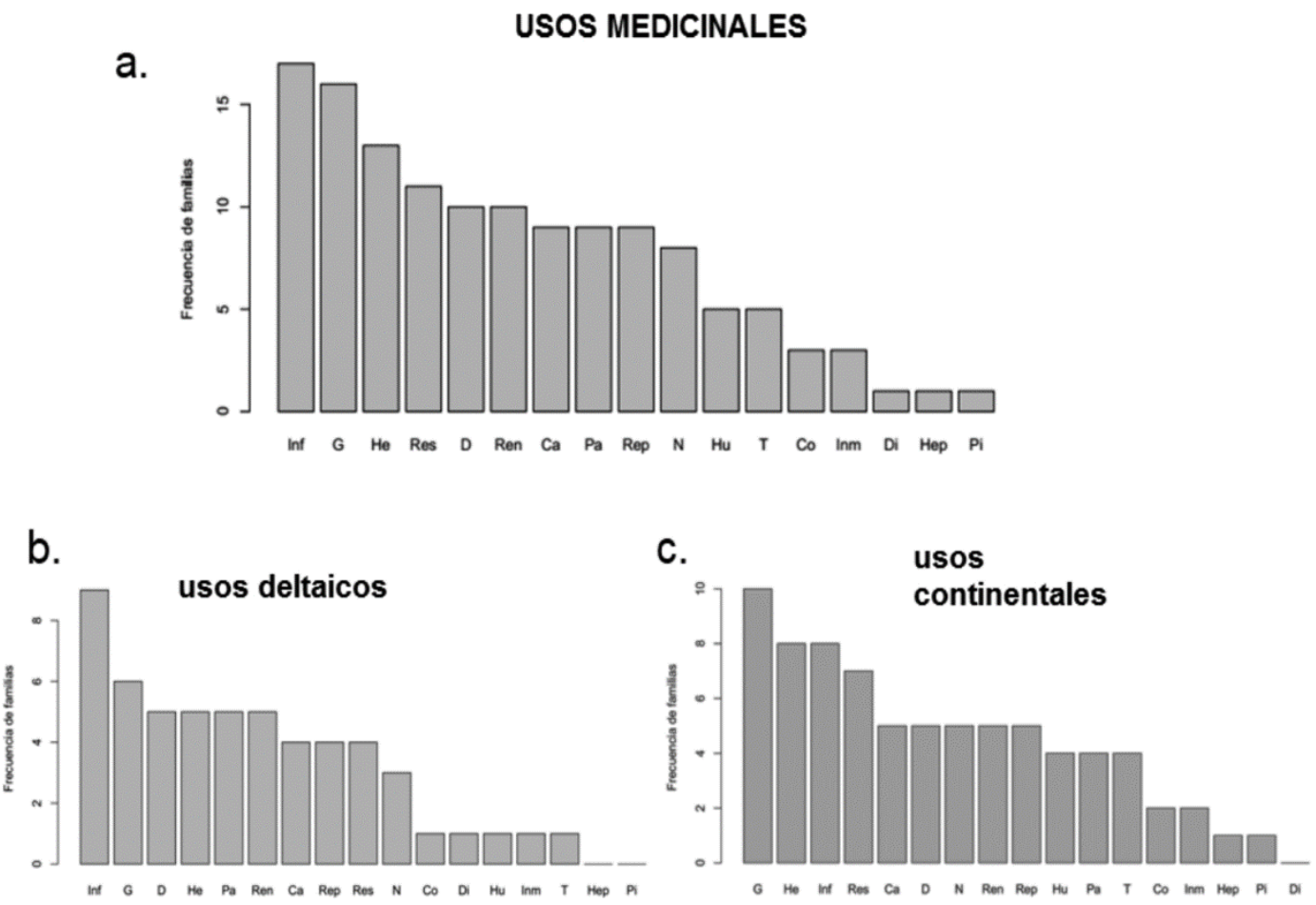

Figura 7. Usos medicinales de acuerdo a la variabilidad taxonómica registrada. a:Usos medicinales inferidos de acuerdo a la riqueza taxonómica total. b:Usos medicinales inferidos de acuerdo a la variabilidad taxonómica de los registros arqueobotánicos de los cerritos emplazados en la zona deltáica del río Paraná. c:Usos medicinales inferidos de los registros arqueobotánicos procedentes de los cerritos emplazados en los humedales del este de Uruguay, cuenca del río Tacuarembó y margen occidental del bajo río Uruguay.

Generalmente, en arqueología, la asociación: evidencias vegetales termoalteradas - recurso combustible, es dominante. Los análisis desarrollados, nos permitirían considerar que los cerriteros tuvieron una estrategia generalista en la selección de recursos combustibles, si consideramos la variabilidad taxonómica registrada en el contexto fuego y la comparamos con la selección de los recu rsos vegetales que fueron procesados o almacenados por los artefactos culturales (Figura 5). Aunque, este resultado, pudo verse influido, por un lado, por una mayor precisión en las resoluciones paleoantaracológicas y paleocarpológicas en la identificación de grupos taxonómicos, frente a las limitaciones que presentan los análisis de microrestos arqueobotánicos (COLOBIG et al., 2015; DEL PUERTO, 2015). Por otro lado, cabe considerar, la trayectoria histórica de los recursos botánicos en los contextos domésticos, en los cuales, la termoalteración por su poder combustible, se ubica generalmente en el tramo final de la vida útil del recurso (BABOT, 2009). Sin embargo, a los fines de este trabajo, queremos enfatizar que casi todas las taxa arqueobotánicas reconocidas mediante el análisis de evidencias macroscópicas y que caracterizan al contexto fuego aquí consignado, tienen propiedades medicinales reconocidas por la literatura etnobotánica de referencia (Tabla 6). Solo una excepción irrumpe en esta generalidad, y corresponde a la familia Rhamnaceae, cuyas evidencias fueran reconocidas por Inda y del Puerto (2007) para el cerrito 2 de PSL (Id. 5 Tabla 1). Asimismo, algunas de las taxa que integran al contexto fuego, poseen diversas propiedades de interés cultural. Entre ellas, Schinus molle L. (familia Anacardiaceae) cuyas semillas, son utilizadas como saborizantes y conservante de alimentos, así como también, las especies que proporcionan frutos comestibles (Ex: de las familias: Berberidaceae, Myrtaceae, Sapotaceae, Solanaceae). Por lo cual, podríamos considerar que, las presencias de estos recursos en las unidades domésticas analizadas, podrían haber ingresado con otros fines que el combustible, entre estos, por sus propiedades alimenticias y/o medicinales. Es sobre esta última utilidad, que vincularemos nuestro listado y asociación arqueobotánica resultante, como aporte a la farmacopea nativa (ARENAS, 2009; ARIAS y TRILLO 2014) de la SUCURPLA.

Un recurso botánico puede ser utilizado como alimento o como medicina dependiendo de cómo se prepare y el objetivo de uso. La dificultad de encontrar diferencias entre los usos medicinales y alimenticios, dado una fuerte superposición, llevan a entender la presencia de un continuo alimentomedicina en la teoría etnobotánica (FERREIRA et al., 2017; POCHETTINO et al., 2011). En la 
variabilidad taxonómica observada, los microregistros analizados (biosilíceos y almidones), proveen un fuerte respaldo dicha teoría. Al continuo comer - curar (POCHETTINO et al., 2011), aportan las especies identificadas e integrantes de las familias de: Poaceae, Fabaceae, Cannaceae, Arecaceae, Cucurbitaceae (Tabla 6), que definen la correspondencia hallada entre los artefactos arqueológicos (Figura 3).

La asociación funcional de los contenedores cerámicos y artefactos de molienda a la manufactura, procesamiento, consumo y almacenamiento de alimentos es ampliamente reconocida por la arqueología regional (BONOMO et al., 2012; CAPDEPONT, 2013; CAPDEPONT et al., 2002, 2005; SILVA, 2019; IRIARTE, 2003). A esta asociación y dada la correlación en las taxa botánicas reconocidas entre el conjunto artefactual, que se aprecia en la Figura 5, sumamos desde nuestros resultados, a la cuchara cerámica. Este instrumento, fue objeto de estudio específico por Bonomo et al. (2012), dado que, el morfotipo, que constituye una variante morfológica de los cuencos y escudillas cerámicas que caracterizan, entre otros productos tecnológicos, a la entidad arqueológica Goya Malabrigo (SILVA, 2019), no tenía funcionalidad arqueológica reconocida. Mediante diferentes vías de análisis: tecnomorfológicas, químicas, paleobotánicas, Bonomo et al. (2012) infieren que la cuchara de cerámica procedente del sitio CTV (ID: 16 en Tabla 1) debió ser empleada para "calentar y beber líquidos hechos a base de vegetales" (BONOMO et al., 2012, p. 31). Volviendo entonces, a nuestro resultado, si a los contenedores cerámicos y artefactos de molienda se les atribuyen funciones vinculadas a prácticas culinarias asociadas a la alimentación, entonces, la cuchara, comparte esos vínculos. Ahora bien, lo compartido en los artefactos culinarios son taxa botánicas que no solo tienen propiedades alimenticias, sino que también, tienen propiedades para el tratamiento de dolencias y/o mantenimiento de la salud. Por lo cual, y retomando el continuo comer - curar, los artefactos tales como: contenedores cerámicos, morteros y cucharas pudieron integrar el conjunto instrumental (total o parcial) necesario para el desarrollo de prácticas medicinales dirigidas a interferir (potenciar o debilitar) en las propiedades de Poaceae, Fabaceae, Cannaceae, Arecaceae, Cucurbitaceae para el tratamiento de dolencias o mantenimiento de la salud.

De los contextos de procedencia de las evidencias arqueobótanicas nos resta discutir la presencia de los microrestos contenidos en la matriz sedimentarias de las unidades de análisis. Considerando que para la construcción de los cerritos se procedió a la selección de los sedimentos de lugares próximos o distales de sus áreas de emplazamiento (vide supra acápite 2), su contenido arqueobotánico nos conecta con la disponibilidad ambiental de los recursos vegetales con propiedades terapéuticas. Al respecto, del Puerto (2011) recopila la información etnobotánica "presente y pasada de grupos indígenas americanos, con especial hincapié en parcialidades de la cuenca del Plata." (DEL PUERTO, 2011, p. 25) y reporta que: de un total de 130 especies botánicas nativas que se desarrollan en los HEU, el 53\% de estas, cuentan con información etnobotánica que refiere a su utilización medicinal. Para la zona deltaica del río Paraná, se reconoce la presencia de 321 especies botánicas nativas, de las cuales $c a$. el $23 \%$ tienen propiedades potencialmente comestibles de acuerdo a los resultados presentados por Madanes et al. (2013). En tanto que, los estudios realizados por Rodríguez et al. (2013) en Parque Nacional Pre - delta, área donde se emplaza el sitio CTV (Id 16, Tabla 1), destacan que el $65 \%$ del total de especies presentes $(\mathrm{N}=322)$ tienen potencial uso medicinal reconocido, correspondiendo el $71 \%$ a especies nativas. En este trabajo, de las 13 taxa arqueobótanicas contenidas en los sedimentos, 10 tienen propiedades medicinales reconocidas y solamente son tres (Bromeliaceae, Marantaceae, Podostemaceae) los taxones para los cuales no disponemos de referencias. Este resultado estaría reforzando el carácter selectivo en la variabilidad de los recursos vegetales que ingresan a los espacios domésticos, contribuyendo a la consideración de que los mismos, "[...] son los escenarios en los cuales, la farmacopea tiene un lugar preponderante." (ARENAS, 2009, p. 87).

Una vez reconocida la disponibilidad de recursos botánicos con propiedades medicinales, en las áreas donde se emplazan los cerritos de la SUCURPLA y a efectos de avanzar en los restantes requerimientos de una investigación paleoframacológica (al respecto, CHAVEZ y REINHARD, 2003; REINHARD, 2000), debemos enfocarnos en las necesidades sanitarias que pudieron ser llamadas a cubrir estos recursos. Entre los requerimientos, se encuentra el conocimiento respecto a cuáles fueron las enfermedades o dolencias que afligieron a las poblaciones de estudio.

Las investigaciones bioarqueológicas desarrolladas a partir de restos óseos humanos de los cerriteros que ocuparon la HEU sintetizadas en Figueiro (2014), dan cuenta que el 57\% de los individuos cuyos restos fueron exhumados presentaban caries. Registrando una alta correlación en la 
presencia de caries, con lesiones periapicales y pérdida de dientes antemortem. Refiere también, a que, de forma aislada, se observan evidencias de procesos infecciosos plausibles de ser relacionados a periostitis y osteomielitis en extremidades inferiores. En forma relativamente regular, se detecta la presencia de alteraciones articulares (osteoartritis) y lesiones traumáticas. Por su parte, los datos biorqueológicos desarrollados sobre restos óseos humanos recuperados en los sitios deltaicos, aportan evidencias para sustentar problemáticas sanitarias vinculadas al desarrollo de patologías infecciosas (RAMOS VAN RAPP y SCABUZZO, 2018). Al respecto, Scabuzzo et al. (2015) establecen que las causas de estas infecciones podrían ser diversas y estar vinculadas con episodios traumáticos localizados, o con la incidencia de algún tipo de agente sistémico. Se registran también, evidencias de reacciones periósticas, osteomielitis y treponematosis (SCABUZZO et al., 2015; RAMOS VAN RAPP y SCABUZZO, 2018). Otra paleopatología con alto grado de relevamiento en las investigaciones bioarqueológicas en esqueletos de cerriteros deltaicos y margen occidental del bajo río Uruguay, se asocia a enfermedades degenerativas de las articulaciones u osteoartritis (SCABUZZO y RAMOS VAN RAAP, 2019).

Para completar el panorama sanitario de las poblaciones que vivieron vinculadas a la zona de humedales de la SUCURPLA y cuyas dolencias o enfermedades no pueden reconocerse mediante estudios osteológicos, apelamos para discutir nuestros resultados a registros proxies. Estos registros, proceden de investigaciones etnoecológicas y etnomédicas desarrolladas en la zona de humedales del Río de La Plata (HERNÁNDEZ y ARAMBARRI, 2011; HERNÁNDEZ et al., 2009, 2015) y otras regiones sometidas a estrés hidrológico (MARTINEZ, 2011; MARTINEZ et al., 2014).

Mayoritariamente, la medicina popular de los habitantes del litoral costero platense, recure al uso terapéutico de plantas para cubrir trastornos digestivos, epidérmicos y respiratorios (HERNÁNDEZ et al., 2015). Sin embargo, en áreas donde la vulnerabilidad hidrológica afecta episódicamente, la calidad hidroquímica del agua, su accesibilidad y disponibilidad, el uso de plantas medicinales es requerido mayoritariamente para mitigar dolencias vinculadas a patologías infecciosas, gastrointestinales y parasitarias (MARTINEZ, 2011; MARTINEZ et al., 2014).

En nuestros resultados de acuerdo a las asociaciones de los principales usos medicinales obtenidos (Figura 7), podemos establecer que los cerriteros recurrieron mayoritariamente a los recursos botánicos para el tratamiento de infecciones. Aspecto que, tiene asociación con los resultados bioarqueológicos reseñados. Por lo cual, el listado de taxa arqueobotánicas que tienen propiedades terapéuticas para incidir en este tratamiento (vide Tabla 6), serían las que dominarían la farmacopea cerritera. Por su parte, los cuadros de afecciones gastrointestinales, no tienen un registro osteológico asignable, sin embargo, de acuerdo a los proxies actuales y el lugar que ocupa en nuestros resultados, es posible considerar que la farmacopea de los cerriteros, concibiera prácticas médicas para enfrentar la vulnerabilidad hidrometeorológica. Una mayor vulnerabilidad, caracteriza particularmente a los territorios del delta del río Paraná. Al respecto, las diferencias marginalmente significativas entre los registros continentales y deltaicos podrían correlacionarse a que problemáticas hídrico - sanitarias habrían tenido una mayor incidencia en la salud de los cerriteros deltaicos.

\section{CONCLUSIONES}

En este trabajo hemos puesto en evidencia que existe en una escala temporal y espacial amplia, ciertas regularidades en la presencia de algunos recursos botánicos con propiedades terapéuticas reconocidas para la salud, en el registro arquebotánico de los cerritos emplazados en la SUCURPLA. Especies de las familias: Poaceaes, Fabaceae, Arecaceae, Cannanaceae, pudieron constituir en el sistema medicinal cerritero, los recursos básicos para intervenir en afecciones y dolencias. Esta misma asociación arqueobotánica, caracteriza al conjunto artefactual analizado, por lo cual, estos artefactos: contenedores cerámicos, cucharas y morteros podrían haber constituido parte del instrumental (tool kit) necesario para potenciar las propiedades terapéuticas o facilitar las estrategias de aplicación y consumo. En términos generales, los usos medicinales que cuentan con mayor frecuencia en nuestro estudio se relacionan con su poder de intervenir en: infecciones, en problemáticas gastrointestinales, respiratorias y dolores. Estas afecciones encuentran respaldo en los resultados bioarqueológicos en cuanto a la presencia de marcadores de estrés ocupacional, fisiológico $\mathrm{y}$ funcional en las poblaciones cerriteras y con los resultados provistos por las investigaciones etnobotánicas y etnomédicas desarrolladas en poblaciones actuales que ocupan áreas hidrometerológicas vulnerables. A pesar de la alta representación en el registro arqueobotánico cerritero de recursos botánicos con propiedades medicinales y la alta disponibilidad ambiental en la 
oferta variada de estos recursos en las áreas de emplazamiento de los cerritos, la farmacopea arqueológica o también concebida como paleofarmacopea, no ha sido objeto particular de estudio. Es en este sentido que este trabajo ha pretendido contribuir y generar, expectativas para su desarrollo futuro.

\section{AGRADECIMIENTOS}

Al Dr. Andres Canavero por su asesoramiento en el tratamiento estadístico de los datos. Al Dr. Eduardo Apolinaire por su contribución a la confección de imágenes que ilustran el manuscrito y sus aportes a la resolución inferencial. Esta investigación contó con los subsidios del Proyecto: Préstamo BID - PICT 2723 de la Agencia Nacional de Promoción Científica Tecnológica.

\section{REFERENCIAS}

ALONSO, E.; BASSAGODA, M. J. Los bosques y matorral psamófilos en el litoral platense y atlántico del Uruguay. Comunicaciones botánicas del Museo de Historia Natural de Montevideo, Montevideo, v. 113, n. 4:1-12, 1999 .

ALONSO, J.; DESMARCHELIER, C. Plantas medicinales autóctonas de la Argentina. Bases científicas para su aplicación en atención primaria de la salud. Rosario: Corpus Libros Médicos y Científicos, Corpus Editorial, 2015, $663 \mathrm{p}$.

ALVAREZ, M.A. Pharmacological properties of native plants from Argentina. Springer Cham, Switzerland, 2019, $255 \mathrm{p}$.

AMATO, S.; SILVA, A. Estratigrafía cuaternaria del subsuelo de la Cuenca inferior del río Paraná. RAGA, Buenos Aires, v. 64, n. 4, p. 594-602, 2009.

AMEGHINO, F. La Antigüedad del Hombre en el Plata. Vol. 1, Buenos Aires: Igon Hermanos, 1880$1881,640 \mathrm{p}$.

APOLINAIRE, E.; BASTOURRE, L. Nets and canoes: A network approach to the pre-Hispanic settlement system in the Upper Delta of the Paraná River (Argentina). Journal of Anthropological Archaeology, Amsterdam, n. 44, 56-68, 2016.

ARECHAVAlETA, J. Viaje a San Luis. En: Figueira, J. H.; Dornaleche, Reyes (Eds.) Uruguay en la Exposición Histórica de Madrid, Montevideo: Imprenta Artística Americana, 1892, 65-91 p.

ARENAS, P. Los estudios sobre medicina y farmacopea vernácula en el Gran Chaco. Rojasiana, Asunción, v.8, n.2, p. 81-100, 2009.

ARIAS, T.B.; TRILLO, C. Animales y plantas que curan: avances sobre la farmacopea natural de los pobladores del área de Laguna Mar Chiquita.Revista facultad de ciencias exactas, físicas y naturales, Córdoba, v.1, n. 2, p.77-85, 2014.

ARRILLAGA DE MAFFEI, B. Plantas usadas en medicina natural. Montevideo: Hemisferio Sur, 1997, $152 \mathrm{p}$.

BABOT, M. P. La cocina, el taller y el ritual: explorando las trayectorias del procesamiento vegetal en el noroeste argentino. Darwiniana, Buenos Aires, v.47, n.1., p. 7-30, 2009.

BARRENECHE J.M. Y ZARUCKI M. Mapeo y Clasificación del sitio Ramsar Bañados del Este y Franja Costera. Rocha, PROBIDES, 2017, 200 p.

BASTOURRE, M. Estudios arqueofaunísticos en el Delta Superior del Paraná: el sitio Los Tres Cerros 1 (Provincia de Entre Ríos, Argentina). Revista Chilena de Antropología, Santiago de Chile, n. 30, p. 109-115, 2014 $798 \mathrm{p}$.

BAUZÁ, P. Historia de la dominación española en Uruguay. 2 ed., Montevideo: Barreiro y Ramos, 1895,

BILENCA, D.; MIÑARRO, F. Identificación de áreas valiosas de pastizal (AVPs) en las Pampas y Campos de Argentina, Uruguay y sur de Brasil. Buenos Aires: Fundación Vida Silvestre, 2004, p. 353.

BÓ, R. Ecorregión Delta e Islas del Paraná. En: Brown, A., Martínez Ortiz, U., Acerbi, M., Corcuera, J.

(Eds.), Situación Ambiental Argentina. Fundación Vida Silvestre, Buenos Aires, 2006, p. 131-143.

BÓ, R., KALENSNIK, F., QUINTANA, R. Flora y Fauna silvestre de la porción terminal de la cuenca del

Plata. Consideraciones ecológicas y biogeográficas. En: Bortahagaray J.M. (Comp.) El río de la Plata como territorio. Ediciones Infinito, Buenos Aires, 2002, p. 100-124.

BONOMO, M. Historia Prehispánica de Entre Ríos. Bueno Aires: Fundación de Historia Natural Felix de Azara, Universidad Maimónides, 2012, 87 p.

BONOMO, M., CASTRO, J.C., SILVA, C. Tecnología y subsistencia en el sitio arqueológico Cerro Tapera Vázquez (Parque Nacional Pre Delta, República Argentina) Cadernos do Lepaarq, Pelotas, n. 22, p. 64-92, 2014. 
BONOMO, M.; COLOBIG, M.; MAZZI, N. Análisis de residuos orgánicos y microfósiles siliceos de la "cuchara" de cerámica del sitio Cerro Tapera Vázquez (Parque Nacional Pre-Delta, Argentina). R. Museu. Arqu. Etn., São Paulo, v. 22, p. 31-50, 2012.

BONOMO, M.; COLOBIG, M.; PASSEGGI, E.; ZUCOL, A; BREA, M. Multidisciplinary studies at Cerro Tapera Vázquez site, Pre-Delta National Park, Argentina: The archaeological, sedimentological and paleobotanical evidence. Quaternary International, Amsterdam, n. 245: 48-61, 2011a.

BONOMO, M.; DI PRADO, V.; SILVA, C.; SCABUZZO, C.; RAMOS VAN RAPP, A.; CASTIÑEIRA, C.; COLOBIG, M.; POLITIS, G. Las poblaciones indígenas prehispánicas del río Paraná Inferior y Medio. Revista del Museo de La Plata, La Plata, v. 4, n. 2, p. 575-610, 2019.

BONOMO, M.; POLITIS, G; GIANOTTI, C. Montículos, Jerarquía social y Horticultura en las sociedades indígenas del delta del río Paraná (Argentina). Latín American Antiquity, Cambridge, v. 22, n.3, p. 97-333, $2011 b$.

BONOMO, M; POLITIS, G.; CASTRO, JC. Primeros resultados de las investigaciones arqueológicas en el delta superior del Paraná y su contribución al atlas arqueológico de la Provincia de Entre Ríos. Folia Histórica del Nordeste, Resitencia, n.18, p. 33-58, 2010.

BONOMO, M., SCABUZZO, C., POLITIS, G., ZUCOL, A. Stable carbon and nitrogen isotope studies in the Paraná river delta (Argentina): an approach to prehispanic diets. Latin American Antiquity, Cambridge, v.28, n. 1, p.105-126, 2017.

BORCARD, D.; GILlET, F. O.; LEGENDRE, P. Numerical Ecology with R. New York: Springer Verlag, 2011, 306 p.

BRACCO, R. Montículos de la cuenca de la Laguna Merín: tiempo, espacio y sociedad. Latin American Antiquity, Cambridge, v. 17, n. 4, p. 511-540, 2006.

BRACCO, R. Lo crudo y lo cocido. Una nueva aproximación a los "cerritos de indios". Revista Uruguaya de Antropología y Etnografía, Montevideo, v. 2, p. 39-55, 2019a.

BRACCO, R.; DEL PUERTO, L.; INDA, H. Prehistoria y Arqueología de la Cuenca de Laguna Merín. En: Loponte, D.; Acosta, A. (Eds.) Entre la tierra y el agua: arqueología de humedales de Sudamérica. Buenos Aires: AINA, 2008, p. 1-59.

BRACCO, R.; DEL PUERTO, L; INDA, H; PANARIO, D.; CASTIÑEIRA, C.;GARCÍA-RODRÍGUEZ, F. The Relationship Between Emergence of Mound Builders in SE Uruguay and Climate Change Inferred from Opal Phytolith Records. Quaternary International, Amsterdam, v.1, n. 245, p. 62-73, 2011.

BRACCO, R.; INDA, H.; DEL PUERTO, L. Complejidad en montículos de la cuenca de la laguna Merín y análisis de redes sociales. Intersecciones en Antropología, Olavarría, n. 16, p. 271-286, 2015.

BRACCO, R.; MONTAÑA, J.; NADAL, O.; GANCIO, F. Técnicas de Construcción y Estructuras Monticulares, Termiteros y Cerritos: de lo Arqueológico a lo Estructural. En: Durán, A. y Bracco, R. (Eds.) Arqueología de las Tierras Bajas, Ministerio de Educación y Cultura, Montevideo, 2000, p. 285-300.

BRACCO, R.; PANARIO, D.; GUTIÉRREZ, O.; DUARTE, C.; y BAZZINO, A. Estructuras monticulares y hormigueros en el sur de la Cuenca de la Laguna Merín: ¿ingenieros ambientales y/o la estrategia del bricoleur?

Revista de Antropología del Museo de Entre Ríos, Paraná, v. 5, n. 1, p. 24-40, 1999b.

BRACCO, R.; URES, C. Ritmos y dinámica constructiva de las estructuras monticulares. Sector Sur de la Cuenca de la Laguna Merín - Uruguay. En: López Mazz J.M. y Sans M (compliladores). Arqueología y Bioantropología de las Tierras Bajas. Montevideo: Universidad de la República Facultad de Humanidades y Ciencias de la Educación, 1999, p.13-33.

BRAZEIRO, A. Bosques de Uruguay: Necesidades de investigación para la gestión sustentable y conservación.En: Brazeiro, A. (Ed.) Recientes avances en investigación para la gestión y conservación del bosque nativo de Uruguay. Montevideo: Facultad de Ciencias y Ministerio de Ganadería Agricultura y Pesca, 2018, p. 12-16.

BRAZEIRO, A.; ACHKAR M.; CANAVERO, A., FAGÚNDEZ, C.; GONZÁLEZ, E.; GRELA, I.; LEZAMA, F.; MANEYRO, R.; BERTHESAGHI, L.; CAMARGO, A.; CARREIRA, S.; COSTA, B.; NUÑEZ, D.; DA ROSA, I.; TORANZA, C. Prioridades geográficas para la conservación de la biodiversidad terrestre de Uruguay. Resumen Ejecutivo Proyecto PDT 32-26. Montevideo, 2008, 46 p. Disponible en: http://www.universidadur.edu.uy/retema/grupos.html\#ar: Acceso en enero 2020.

BREA, M.; FRANCO, M.; BONOMO, M.; POLITIS, G. Análisis antracológico del sitio arqueológico Los Tres Cerros 1 (Delta Superior del río Paraná), provincia de Entre Ríos. Revista del Museo de La Plata, La Plata, v.13, n.78, p. 345-360, 2013

BRUSSA, C.A.; GRELA, G. Flora arbórea Del Uruguay, con énfasis en las especies de Rivera y Tacuarembó. Montevideo: Cofusa, 2007, 544 p.

BURKART A. Ojeada sinóptica sobre la vegetación del delta del río Paraná. Darwiniana, Buenos Aires, v.11, n.3, p. 457-561, 1957.

CABRERA, L. Funebria y sociedad entre los constructores de cerritosdel Este uruguayo. En: López Mazz, J.M. y Sans, M. (Eds.) Arqueología y bioantropología de lastierras bajas. Montevideo: Facultad de Humanidades y Ciencia de la Educación, Universidad de la República, 1999, p. 63-78. 
CABRERA, L. Construcciones en tierra y estructura social en el Sur del Brasil y Este de Uruguay (ca. 4.000 a 300 a. A.P.) Techne, La Plata n.1, p. 25-33, 2013.

CABRERA, L.; CURBElO, C. Sitio CH2D01, Área de San Miguel, Depto. de Rocha, R.O. del Uruguay. Estructura de sitio y zonas de actividad. Revista do CEPA,Santa Cruz do Sul, n.17, p. 333-344, 1990.

CABRERA, L.; DURÁN,A.; FEMENÍAS, J; MAROZZI, O. Investigaciones arqueológicas en el sitio CG14E01 ("Isla Larga”) Sierra de San Miguel. Depto. Rocha. Uruguay. En: Durán, A.; Bracco, R. (Eds) Arqueología de las Tierras Bajas, Montevideo: Ministerio de Educación y Cultura, 2000, p. 183-194.

CAPDEPONT, I. Arqueología de sociedades indígenas del litoral del río Uruguay. Paisajes y ocupaciones humanas. Latvia: Editorial Publicia, 2013, 312 p.

CAPDEPONT, I. En el interior de la cerámica. Técnica de Corte en Lámina Delgada. 1996, 130 p. Trabajo Monográfico para Técnicas en Investigación Arqueológica (Licenciatura en Arqueología), Facultad de Humanidades y Ciencias de la Educación, Universidad de la República - Montevideo.

CAPDEPONT, I.; CASTIÑEIRA, C., DEL PUERTO, L.; FERNANDEZ, G. Desarrollo de las ocupaciones humanas durante el Holoceno en la cuenca de la Lagua de Castillos (Uruguay): síntesis y actualización de las investigaciones arqueológicas. Tessituras, Pelotas, v.4, n.1, p. 53-93, 2016.

CAPDEPONT, I.; DEL PUERTO, L.; INDA, H. Instrumentos de molienda: evidencias del procesamiento de recursos vegetales en la laguna de Castillos (Rocha, Uruguay). Intersecciones en Antropología, Olavarría, n.6, p. 153-166, 2005.

CAPDEPONT, I.; INDA, H.; DEL PUERTO, L. Caracterización tecnológica y funcional del material cerámico arqueológico de la cuenca de la Laguna de Castillos (Rocha - Uruguay). En: MAZZANTI, D.; BERÓN, M.; OLIVA, F. (Eds.). Del mar a los salitrales: Diez mil años de historia Pampeana en el umbral del tercer milenio. Mar del Plata: Facultad de Humanidades, 2002. p. 41-50.

CAPDEPONT, I.; PINTOS, S. Manifestaciones funerarias de los constructores de cerritos: enterramientos humanos en los túmulos de la Laguna de Castillos, Depto. de Rocha, Uruguay. En: MAZZANTI, D.; BERÓN, M.; OLIVA, F. (Eds.). Del mar a los salitrales: Diez mil años de historia Pampeana en el umbral del tercer milenio. Mar del Plata: Facultad de Humanidades, 2002. p. 107-120.

CAPDEPONT. I.; PINTOS, S. Manejo y aprovechamiento del medio por parte de los grupos constructores de montículos: cuenca de la Laguna de Castillos. Revista Relaciones, Buenos Aires, n. 31, p. 117 - $132,2006$.

CASTIÑEIRA, C.; APOLINAIRE, E.; BLASI, A.; POLITIS, G.; BONOMO, M.; BASTOURRE, L.; MARI, F. Pre-Hispanic Settlement in Hydrometeorologically Suceptible Areas during late Holocene: The Upper Delta of the Parana River Case. The Holocene, Swansea, v. 27, n.12: 1801-1811, 2017a.

CASTIÑEIRA, C.; APOLINAIRE, E.; BLASI, A.; POLITIS, G.; BONOMO, M.; MARI, F. Pre-hispanic earthwork engineering variability in the upper delta of the Paraná river. A comparative study between Los Tres Cerros mounds (Entre Ríos province, Argentina). Journal of Archaeological Science: Reports, Amsterdam, v.13: 322-332,2017b.

CASTIÑEIRA, C.; BLASI, A.; BONOMO, M.; POLITIS, G.; APOLINAIRE, E. Modificación antrópica del paisaje durante el Holoceno tardío: las construcciones monticulares en el delta superior del río Paraná. RAGA, Buenos Aires, v.4, n.71, p. 33-47, 2014.

CASTIÑEIRA, C.; BLASI, A; POLITIS, G; BONOMO, M.; DEL PUERTO, L.; HUARTE, R.; CARBONARI, J.; MARI, F.; GARCÍA-RODRÍGUEZ, F. The origin and construction of pre-Hispanic mounds in the Upper Delta of the Paraná River (Argentina). Archaeological and Anthropological Science, New York, v.5, n.1, p. 37-57, 2013.

CASTIÑEIRA, C.; CAPDEPONT, I.; DEL PUERTO, L.; BLASI, A. Aportes de la geoarqueología para el estudio de la variabilidad constructiva prehispánica de cerritos del este uruguayo y el delta del Paraná. En: Rubin de Rubin, J.; Favier Dubois, C. y da Silva, T. (Eds.) Geoarqueología na América do Sul. Goias: Editora da PUC, 2015, p.55-91.

CASTIÑEIRA, C., DI LELLO, C., BLASI, A. Explotación y manejo del recurso sedimentario/ pedológico por los constructores de cerritos del Delta Superior del río Paraná y litoral fluvial de Gualeguaychú-Argentina. Intersecciones en Antropología, Olavarría, v.7, n.21, p.7-21, 2016.

CASTIÑEIRA, C.; PIÑEIRO, G. Análisis estadístico textural para el estudio de las columnas estratigráficas de las excavaciones I y II del Bañado de los Indios. En: Durán, A. y Bracco, R. (Eds.) Arqueología de las tierras bajas. Montevideo: Ministerio de Educación y Cultura, 2000, p. 467-478.

CASTIÑEIRA, E. Etnobotánica aplicada a la conservación en el "Parque Regional Quebradas del Norte", Rivera, Uruguay. 2017.153p. Tesis doctoral. Facultad de Ciencias Naturales y Museo, Universidad Nacional de La Plata, La Plata.

CASTIÑEIRA, E.; CANAVERO, A.; POCHETTINO, M. L. Analysis of the ethnobotanical knowledge network for a priority area for biocultural conservation, Rivera, Uruguay. Ethnobiology and Conservation, Pernambuco, v. 7, n. 4, p. 1-342018.

CASTIÑEIRA, E.; CANAVERO, A.; ARIM, M. Ethnobotanical Knowledge Complexity in a

Conservation Area of Northern Uruguay: Interlocutors-Medicinal Plant Network and the Structural Patterns of Interaction. Econ Bot, 2020. https://doi.org/10.1007/s12231-020-09491-3, Mayo 2020. 
CASTRO, J.C. Investigaciones arqueológicas en la cuenca media e inferior del río Uruguay (provincia de Entre Ríos). 2017. 536 p. Tesis (Doctor en ciencias naturales) - Facultad de Ciencias Naturales y Museo, Universidad Nacional de La Plata, La Plata - Provincia de Buenos Aires.

CASTRO, C., CASTIÑEIRA C. Variabilidad temporal de los cerritos del delta superior del río Paraná. En: Politis, G. y Bonomo, M. (Eds.), Goya-Malabrigo Arqueología de una sociedad indígena del noreste argentino, Tandil: UNICEN, 2018, p.107-127.

CASTRO, J.C., CASTIÑEIRA, C. Estudio de la secuencia sedimentaria de la localidad arqueológica Cerros de Boari (Gualeguaychú, Entre Ríos). Comechingonia, Córdoba, v.21, n. 2, p. 75-97, 2017.

CASTRO, J.C., DEL PAPA, M. La estructura del registro bioarqueológico del río

Uruguay inferior. Análisis de la colección osteológica humana del Museo Arqueológico Manuel Almeida (Gualeguaychú, Entre Ríos). Intersecciones en Antropología, Olavarría, v.16, p. 195-205, 2015.

CAVALLOTTO, J.L. Evolución holocena de la llanura costera del margen sur del Río de la Plata. RAGA, Buenos Aires, v. 57, n. 4, p. 376-388, 2002.

CAVAllotTO, J., VIOLANTE, R., PARKER, G. Sea level fluctuation during the last 8600 yr sin the Río de la Plata (Argentina). Quaternary International, Amsterdam, v. 114, n. 1, p. 55-165, 2004.

CHAVEZ, S.; REINHARD, K. Paleopharmacology and pollen: Theory, method and application. Mem. Inst.

Oswaldo Cruz, Río de Janeiro, v.98, n.1, p.207-2011, 2003.

CHEBATAROFF, J. La vegetación del algarrobal, monte espinoso del litoral, I. Divisiones de la Provincia Fitogeográfica Uruguayense. En: Jornadas de Ciencias Naturales, Facultad de Humanidades y Ciencias, 1980, Montevideo, p. 77-78.

COLOBIG, M.; SÁNCHEZ, J.; ZUCOL, A. Análisis de macrorrestos vegetales en el sitio arqueológico Los Tres Cerros 1 (Isla las Moras, Victoria, Entre Ríos). Revista del Museo de Antropología, Córdoba, v.8, n.1, p. 115-124, 2015. \}

CONVENCIÓN RAMSAR. The convention on wetlands tex as originally adopeted in 1971.Disponible en: https://www.ramsar.org/document/the-convention-on-wetlands-text-as-originally-adopted-in-1971. Acceso en 22 del 52020.

DANGAUS, N. Los ambientes acuáticos de la Provincia de Buenos Aires. En: Barrio R, Etcheverry R, Caballe M, LLamvías E (Eds). Geología y Recursos Minerales de la Provincia de Buenos Aires. Relatorio de XVI Congreso Geológico Argentino, La Plata: AGA, 2005, p. 219-236.

DE SOUZA LIMA - RIBEIRO, M.; BARBERI, M. Análisis palinológica: fundamentos y perspectivas na pesquisa arqueológica. Habitus, Goiânia, v.3, n.2, p.261-290, 2005.

DEL PUERTO, L. Interrelaciones humano-ambientales durante el Holoceno tardío en el este del Uruguay: cambio climático y dinámica cultural. 2015. 356p.Tesis (Doctorado en ciencias biológicas, opción ecología) - Programa de desarrollo de las ciencias básicas (Pedeciba), Universidad de la República, Montevideo.

DEL PUERTO, L. Ponderación de recursos vegetales silvestres del este del Uruguay: rescatando el conocimiento indígena tradicional. Trama revista de cultura y patrimonio, Montevideo, n.3, p. 22-41, 2011.

DEL PUERTO, L.; CAPDEPONT, I.; INDA, H. Paleobotánica y subsistencia de los constructores de cerritos del Holoceno tardío en el este de Uruguay. Tessituras, Pelotas, v.4,n.1, p. 117-160, 2016 a.

DEL PUERTO, L.; GARCÍA-RODRÍGUEZ, F.; BRACCO, R.; INDA, H.; CAPDEPONT, I.; CASTIÑEIRA, C.; BLASI, A.; FORT, H.; MAZZEO, N. Historia Ambiental y Dinámica Cultural para el Holoceno medio y tardío en el este del Uruguay. En Clave Inter, Montevideo, v. 4: 99-109, 2012.

DEL PUERTO, L., GIANOTTI, C., INDA, H. Gestión del medio y producción de recursos en las tierras bajas del Noreste de Uruguay: análisis paleoetnobotánico del sitio Pago Lindo. Cadernos do LEPAARQ, Pelotas, v.13, n.25, p. 197-222, 2016 b.

DEL PUERTO, L.; INDA, H. Silicofitolitos: Aplicaciones para la reconstrucción de los sistemas de subsistencia prehistóricos. Anales de Arqueología y Etnología, Cuyo, n. 59-60, p. 207-227, 2005.

DI PRADO, V.; CASTRO, C. 2014 Estrategia de remontajes aplicada sobre el registro cerámico del sitio Los Tres Cerros 1 (delta superior del río Paraná). Revista del Museo de Antropología, Paraná, v. 7, n. 2, p. 263 270,2014

DURÁN, A., BRACCO, R. Prólogo. En: Duran, A., Bracco, R. (Eds.) Arqueología de las Tierras Bajas. Montevideo: Ministerio de Educación y Cultura, 2000. p.7-8.

ERICKSON, C. The Domesticated Landscapes of the Bolivian Amazon. En Balée, W., Erickson, C. (Eds.).

Time and Complexity in Historical Ecology: Studies in the Neotropical Lowlands. New York: Columbia University Press, 2006. p. 235-278.

FAGUNDEZ, C.; LEZAMA, F. Distribución espacial de la vegetación costera del litoral platense y atlántico uruguayo: Informe Ferplata. Montevideo: Facultad de Ciencias UDELAR, 2005, 36 p.

FERREIRA, J.W., ZENÓBIA DE OLIVEIRA CAMPOS, L.; PIERONI, A.; ALBUQUERQUE, U.P. Biological and Cultural Bases of the Use of Medicinal and Food Plants. En: Albuquerque, U.P.; De Medeiros, P.; Casas, A. (Ed.). Evolutionary Ethnobiology. Springer International Publishing, Suiza, 2017, p. 176-184.

FIGUEIRA, J. Los primitivos habitantes del Uruguay. En: Figueira, J. H., Dornaleche y Reyes (eds.). Uruguay en la Exposición Histórica de Madrid. Montevideo: Imprenta Artística Americana, 1892, p.161-166. 
FIGUEIRO, G. Bioarqueología en el Uruguay: Situación Actual y Perspectivas Futuras. En: Luna, L; Aranda, C., Suby, J. (Eds). Avances Recientes de la Bioarqueología Latinoamericana, Buenos Aires: GIB, 2014, p. 47-68.

FIGUEIRO, G.; CABRERA, L., LINDO, J.; MALLOTT, E.; OWINGS; MALHI, R.; SANS, M. Análisis del genoma mitocondrial de dos individuos inhumados en el sitio arqueológico CG14E01 "Isla Larga" (Rocha, Uruguay). Revista Argentina de Antropología Biológica, Buenos Aires, v.19, n.1, p. 1-17.

GAUTREAU, P.; LEZAMA, F. Clasificación florística de los bosques y arbustales de las sierras de Uruguay. Ecología Austral, Buenos Aires, v.19, n.2, p. 81-92, 2009.

GIANOTTI, C. Paisajes sociales, Monumentalidad y Territorio en las Tierras Bajas de Uruguay, 2015,695 p. Tesis de doctorado, Facultade de Xeografía e Historia, Universidad de Santiago de Compostela, Santiago de Compostela.

GIANOTTI, C. Intervenciones arqueológicas en el cerrito 27 del conjunto Lemos. TAPA, Santiago de Compostela, n.36, p. 79-98 2005.

GIANOTTI, C. Monumentalidad, ceremonialismo y continuidad ritual. TAPA, Santiago de Compostela, n. 19, p. $87-102,2000$

GIANOTTI, C.; BONOMO, M. De montículos a paisajes: procesos de transformación y construcción de paisajes en el sur de la cuenca del Plata. Comechingonia, Córdoba, v.17, n. 2, p. 129-163, 2013.

GIANOTTI, C.; BARREIRO, D.; PARCERO, C.; OTERO, C.; SUSO, A. La construcción del inventario arqueológico del valle del Yaguarí. TAPA, Santiago de Compostela, n. 36, p. 27-48,2005.

GIANOTTI, C., LÓPEZ, J.M. Prácticas mortuorias en la localidad arqueológica Rincón de los Indios, Departamento de Rocha. En: López y Gascue (Ed.) Arqueología prehistórica uruguaya en el siglo XXI. Montevideo: Facultad de Humanidades y Ciencias de la Educación, Biblioteca Nacional, 2009, p. 218.

GOODY, J. Domestic Groups. En: Addison-Wesley Publishing Company, Indiana, 1972, 32p.

HERNÁNDEZ, M.; ARAMBARRI, A.M. Recursos Fitoterapéuticos y Comportamiento poblacional en dos sectores de la ribera rioplatense de Berisso, Buenos Aires, Argentina. Bonplandia, Corrientes, v. 24, n. 2, p.137148,2011

HERNÁNDEZ, M.; COLARES, M.; CIVITELLA, S. Plantas utilizadas en medicina popular en un sector del Partido de Berisso, Buenos Aires, Argentina. Boletín Latinoamericano y del Caribe de Plantas Medicinales y Aromáticas, Santiago de Chile, n. 8, p. 435- 444, 2009.

HERNÁNDEZ, M.; NOVOA, M.; ARAMBARRI, A.; OVIEDO, M. Plantas medicinales y para condimento usadas en el sudeste del Partido de Berisso (Buenos Aires, Argentina). Bonplandia, Corrientes, v.24, n.2, p. $124-138,2015$

INDA, H.; DEL PUERTO, L. Antracología y subsistencia: paleoetnobotánica del fuego en la prehistoria de la región este del Uruguay - Puntas del San Luis, Paso Barrancas, Rocha, Uruguay. En: Marconetto, B.; Babot, P.; Oliszewski, N.(ed.) Paleoetnobotánica del cono sur: Estudios de caso y propuestas metodológicas, Córdoba: Museo de Antropología FFyH-UNC, 2007, p.137-152.

IRIARTE, J. Mid-Holocene emergent complexity and landscape transformation: the social construction of early formative communities in Uruguay, La Plata basin. 2003, 663 p., Tesis doctoral, College of Arts and Science at the University of Kentucky, Lexington.

IRIARTE, J. La construcción social y transformación de las comunidades del Periodo Formativo temprano del sureste de Uruguay. Boletín de Arqueología PUCP, Lima, n.11, p. 143-166, 2007 a.

IRIARTE, J. Emerging Food-Production Systems in the La Plata Basin: Los Ajos Site. En: Denham, T.; Iriarte, J.; Vyrdaghs, L. (Eds.) Rethinking Agriculture: Archaeological and Ethnoarchaeological Perspectives, Walnut Creek: Left Coast Press, 2007 b, p. 254-270.

IRIARTE, J.; HOLST, I.; LÓPEZ, J.M.; CABEREA, L. Subtropical Wetland Adaptations in Uruguay during the Mid-Holocene: An Archaeobotanical PerspectiveEn: Barbara Purdy (Ed.) Enduring Records: The

Environmental and Cultural Heritage of Wetlands, Oxbow Books, England, 2001, p. 61-70.

IRIARTE, J.; HOLST,I.; MAROZZI, O.; LISTOPAD, C.; ALONSO, E.; RINDERKNECHT, A.; MONTAÑA,

J. Evidence for cultivar adoption and emerging complexity during the mid-Holocene in the La Plata

basin.Nature, Reino Unido, n. 432, p. 614-617, 2004.

IRIONDO, M. The littoral complex at the Paraná mouth. Quaternary International, Amseterdam, v.114, n.1, p. 143-154, 2004.

IRIONDO, M., ALTAMIRANO, L. Delta del Paraná. En: INQUA- CADINQUA (Ed.)

Guía de campo $\mathbf{N}^{\circ}$ 1. Simposio Internacional sobre el Holoceno de América del Sur, 1988, Paraná, p. 13,1988 .

KANDUS, P., QUINTANA, R., BÓ, F. Patrones de paisaje y biodiversidad del Bajo Delta del RíoParaná.Mapa de ambientes.Buenos Aires: Pablo Casamajor, 2006, 48 p.

KOZAMEH, L., TESTA, N., LÓPEZ, M., MANGO, L., CORNAGLIA FERNÁNDEZ, J. Huesos rojos en el delta superior del río Paraná. El caso del sitio arqueológico cerro Grande de la "isla los Marinos" (Entre Ríos, Argentina). En: Politis, G. y Bonomo, M. (Eds.), Goya-Malabrigo Arqueología de una Sociedad Indígena del Noreste Argentino, Tandil: UNICEN, 2018, p.129-148. 
LAHITTE, H.; HURRELL, J.; BELGRAO, M.; JANKOWSKI, L.; HALOUS, P. ; MEHITREIRER, K. Plantas Medicinales Rioplatenses. Buenos Aires: Ediciones LOLA, 1998, 240.

LISTA, R. Les cimetières et paraderos minuanes de la province de Entre-Rios. Revue d'Anthropologie, París, n.1, p. 365-368, 1878.

LÓPEZ, J.M. Construcción del paisaje y cambio cultural en las tierras bajas de la Laguna Merín (Uruguay). En: M. Sans y J.M. López Mazz (Comp.) Arqueología y bioantropología de las Tierras Bajas, Montevideo: Departamento de publicaciones de la UdelaR, Facultad de Humanidades y Ciencias de la Educación, 1999, p. 35- 61.

LÓPEZ, J. M. Las estructuras tumulares (cerritos) del litoral atlántico uruguayo. Latin American Antiquity, Cambridge, n.12, p. 1-25,2001.

LÓPEZ, J.M., AGUIRREZABALA, D.; SOTELO, M., MACHADO, A. Ocupaciones prehistóricas en el litoral atlántico uruguayo. Estudios actuales en la laguna Negra. REMS, Mar del Plata, v.4, p. 43-50, 2011.

LÓPEZ, J. M.; CASTIÑEIRA, C. El sitio arqueológico del Potrerillo de Santa Teresa. Estructura de Sitio y Patrón de Asentamiento en la Laguna Negra. En: Asociación uruguaya de arqueología (Ed.).Arqueología Uruguaya hacia el fin del milenio, Actas del IX Congreso Nacional de Arqueología Uruguaya, Colonia 1997. Montevideo: Gráficos del Sur, 2001, p. 147-161.

LOPEZ, J.M.; DABEZIES, J.M.; CAPDEPONT, I. La gestión de recursos vegetales en las poblaciones prehistóricas de las Tierras Bajas del sureste de Uruguay: un abordaje multidisciplinar. Latin American Antiquity, Cambridge, n. 25, p. 256-272, 2014a.

LÓPEZ, J.M.; GASCUE, A. (Eds.). Arqueología Prehistórica Uruguaya en el Siglo XXI, Montevideo: Biblioteca Nacional y FHCE, 2009, 2018p.

LÓPEZ, J.M.; GASCUE, A.; MORENO, F. La prehistoria del este de Uruguay: cambio cultural y aspectos ambientales. AnMurcia, Murcia, n.20, p. 9-24, 2004.

LÓPEZ, J.M.; GIANOTTI, C. Diseño de proyecto y primeros resultados de las investigaciones realizadas en la localidad arqueológica "Rincón de Los Indios". En: Asociación Uruguaya de Arqueología (Eds.) Arqueología Uruguaya hacia el Fin del Milenio, Montevideo: Gráficos del Sur, 2001, pp. 163-174.

LOPEZ, J.M.; ROSTAIN, S.; MCKEY, D. Cerritos, Tolas, Tesos, Camellones y otros montículos de las tierras bajas de Sudamérica. SAB Revista de Arqueología, Pelotas, v.29, n.1. p. 86-113, 2016.

LÓPEZ, J.M.; SOTELO, M; MAROZZI, O.; AGUIRREZÁBAL, D. Tecnología lítica en el Holoceno Temprano del Este de Uruguay. SAB Revista de Arqueología, Pelotas, v. 2, n.2, p. 170-179, 2014b. LOPONTE, D., ACOSTA A., TCHILINGUIRIÁN, P. Estructuras "monticulares", unidades arqueológicas y falsas premisas en la arqueología del noreste argentino. Anuario de Arqueología, Rosario, n.8, p. 45-78, 2016.

MADANES, N., KALESNIK, F., VARGAS, D. Análisis de los recursos vegetales comestibles del macromosaico de humedales del Paraná inferior del holoceno tardío. Cuadernos del Instituto Nacional de Antropología y Pensamiento Latinoamericano, v.1, p. 196-210, 2013.

MALVAREZ, A. El Delta del Río Paraná como mosaico de humedales. En: Malvarez, A. (Ed.). Tópico sobre humedales subtropicales y templados de Sudámerica. Montevideo: Oficina Regional de Ciencia y Tecnología de la UNESCO para América Latina y el Caribe - ORCYT, 1999, p. 35-54.

MARTÍNEZ, G.Uso de plantas medicinales en el tratamiento de afecciones

transmitidas por el agua en una comunidad toba (Qom) del impenetrable (Chaco, Argentina): Una perspectiva Etnoecológica y sanitaria. Bonplandia, Corrientes, v.20, n.2, p. 329-352, 2011.

MARTINEZ, G.; BECCAGLIA, A.M.; LLINARES, A. Problemática hídrico-sanitaria, precepción local y calidad de fuentes de agua en una comunidad toba (qom) del Impenetrable (Chaco- Argentina). Salud Colectiva, Lanús, v.10, n.2, p. 1-14, 2014.

MEIRELLES, C. Entre lagoas e planicies. Mapeamento de ocupações cerriteiras pré-coloniais nas margens da Lagoa Pequena, Pelotas-RS.2017. 97p. Monografía (Grau de Bacharel em Antropologia com linha de formação em Arqueologia) Universidade Federal de Pelotas, Pelotas.

MINISTERIO DE VIVIENDA ORDENAMIENTO TERRITORIAL Y MEDIO AMBIENTE. Atlas de la cuenca del río Tacuarembó. Montevideo: MVOTMA, 2018.

MILHEIRA, R.; ATTONE, T.; BORGES, C. Construtores de cerritos na Laguna Dos Patos, Pontal da Barra, sul do Brasil: lugar persistente, território e ambiente construído no Holoceno recenté. Latin American Antiquity, Cambridge, v. 30, n.1, p. 35-54, 2019.

NAUE, G. Dados sobre o estudo dos Cerritos na área meridional da Lagoa dos Patos, Rio Grande, RS. Veritas: Revista da Pontificia Universidade Catolica do Rio Grande do Sul, Porto Alegre, v.18, n. 71, p. 246-269, 1973

NENADIC, O.; GREENACRE, M. Correspondence Analysis in R, with two- and three-dimensional graphics: The ca package. Journal of Statistical Software, California, v.20, n.3, p. 1-13, 2007.

PANARIO, D. Geomorfología del Uruguay. Montevideo: Facultad de Humanidades y Ciencias, 1988, 32 p.

PAZ, E., BASSAGODA, M.J. Los bosques y los matorrales psamófilos en el litoral platense y atlántico del Uruguay. Comunicaciones botánicas del museo de historia natural de Montevideo, v.5, n.113, p. 1-12, 1999. 
PIRONDO, A.; MICHLIG, A.; MARTÍN, S.; KELLER, H. Constitution and characteristics of the Ibereño herbolarium: a case study within Iberá wetlands (Corrientes, Argentina).Boletín Latinoamericano y del Caribe de plantas medicinales y aromáticas, Santiago de Chile, v.17, n.2, p. $394-413,2018$.

POCHETTINO, M. L.; ARENAS, P. HURRELL, J. A. Plantas "para comer y curar" Revista Museo, La Plata, n.25: 48-53, 2011.

POLITIS, G.; BONOMO, M.La entidad arqueológica Goya-Malabrigo (Ríos Paraná y Uruguay) y su filiación Arawak. SAB Revista de Arqueología, Porto Alegre, v.25, n.1, p. 10 - 46, 2012.

POLITIS, G.; BONOMO, M. (Eds.) Goya-Malabrigo Arqueología de una sociedad indígena del noreste argentino.Tandil: UNICEN, 2018, $368 \mathrm{p}$

POLITIS,G., BONOMO, M., CASTIÑEIRA, C., BLASI, A. Archaeology of the Upper Delta of the Paraná River (Argentina) : mound construction and anthropicl and scapes in the Los Tres Cerros locality. Quaternary International, Amseterdam, n.245, p. 74-88, 2011.

RAMOS VAN RAAP, A., SCABUZZO, C. A case of nonvenereal treponematosis in a pre-Hispanic adult from northeastern Argentina. International Journal of Osteoarchaeology, Nueva Jersey, n. 28:757-765, 2018.

R CORE TEAM. R: a language and environment for statistical computing. $R$ Foundation for Statistical Computing, Vienna, Austria. Available via http://www.R-project.org., 2017.

REINHARD, K. Paleopharmacology. En: ELLIS, L. (Ed.). Archaeological Method and Theory: An Encyclopedia. Abingdon: Taylor \& Francis Group, 2000. p.443-448.

REINHARD, K.; HEVLY, R.; HAMILTON, D.H. Use of pollen concentration in paleopharmacology:

Coprolite evidence of medicinal plants. Journal of Ethnobiology, Washington, n. 11, p.117-134, 1991.

RODRIGUEZ, E.E; ACEÑOLAZA, P.G.; ZAMBONI L.P.La flora medicinal del Parque Nacional Pre-Delta,

Provincia de Entre Ríos-Argentina. Dominguezia, Buenos Aires, v.29, p. 36.

ROSTAIN, S. Islands in the Rainforest Landscape Management in Pre-Columbian Amazonia.

Routledge: Left Coast Press, Walnut Creek, 2012. 256 p.

ROTH, S. Beobachtungen über Entstehung und Alter der Pampasformation in Argentinien. Zeitschrift der deutschen geologischen Gesellschaft, Band, n. 40, p. 375-464. 1888.

SÁNCHEZ, J., COLOBIG, M., ZUCOL, A., POLITIS,G., BONOMO,M., CASTIÑEIRA,C. Primeros resultados sobre el uso prehispánico de los vegetales en el sitio arqueológico Los Tres Cerros 1 (Victoria, Entre Ríos, Argentina): análisis del registro biosilíceo. Darwiniana, Buenos Aires, v.1, n.2: 201-219, 2013.

SANS, M. Pautas de adaptación en el Este de Uruguay a partir del estudio de los restos esqueletarios humanos En: López, J.M. y Sans, M. (Eds.), Arqueología y Bioantropología de las Tierras Bajas, Montevideo: Facultad de Humanidades y Ciencia de la Educación, Universidad de la República, 1999, p.107126.

SAYAGUES, L., GRAF, E.; DELFINO, L. Análisis de la información publicada sobre composición florística de montes naturales del Uruguay. Agrociencia Uruguay, n.7: 96-110, 2000.

SCABUZZO, C.; RAMOS VAN RAAP. Alcances y limitaciones en el relevamiento de osteoartrosis. Primeros resultados de los análisis en series osteológicas del sur de Entre Ríos (Argentina). En: FABRA, M., NOVELLINO, P., ARRIETA, M., SALEGA, M. Metodologías para el estudio de restos esqueletales en argentina: actualizaciones y nuevas perspectivas. Córdoba: Universidad Nacional de Córdoba, Facultad de Filosofía y Humanidades, 2019. p. 124.

SCABUZZO, C.; RAMOS VAN RAAP. New results of the osteological studies of the los Tres Cerros 1 site (upper delta of Paraná). Comechingonia, Córdoba, v. 21, n. 2, p. 201-228, 2018.

SCABUZZO, C.; RAMOS VAN RAAP, M.A.; BONOMO, M.; G. POLITIS. Estudios bioarqueológicos en el sitio Los Tres Cerros 1 (Delta Superior del río Paraná, Entre Ríos, Argentina). Boletim do Museu Paraense Emílio Goeldi. Ciências Humanas, Paraná,v. 10, n. 2, p. 509- 535, 2015.

SCARPA, G., ANACONATANI, L. Etnobotánica histórica de las misiones franciscanas del este de Formosa II: identificación y análisis de datos inéditos y reelaboración integral de fuentes ya publicadas a partir de hallazgos documentales. Dominguezia, Buenos Aires, v.32. n. 2, p. 37-79, 2017

SCARPA, G.; ROSSO, C. Etnobotánica histórica de grupos criollos de Argentina IV: Identificación taxonómica de las plantas y análisis de datos medicinales del Chaco húmedo provenientes de la encuesta nacional de folklore de 1921. Bonplandia, Corrientes, v.28, n.1, p. 5-42, 2019.

SILVA, C. Formas cerámicas Goya-Malabrigo: variabilidad y tipos morfológicos. En: Politis, G. y Bonomo M. (ed.) Goya Malabrigo arqueología de una sociedad indígena del noroeste argentino, Unicen, Olvarría, 2019, p.: 73-87.

SORIANO, A. Rio de la Plata Grasslands. En: Coupland, R.T. (Ed.). Ecosystems of the World: Natural

Grasslands. Introduction and Western Hemisphere. Elsevier, Amsterdam, 1991, p. 367-369.

STUIVER, M., REIMER, P.J. Calib radiocarbon calibration program. Radiocarbon, Arizona, n.35, p. 215230, 1993.

SUAREZ, X. ¿Existió la monumentalidad en tierra entre los cazadores - recolectores del este uruguayo? Propuesta metodológica para el estudio de las construcciones antópicas en tierra. Arqueología Sudamericana, Popayán, v. 2, n. 2, p. 263-290, 2006. 
TABAKIAN, G. Estudio comparativo de plantas medicinales vinculadas a tradiciones indígenas y europeas en Uruguay. Bonplandia, Corrientes, v.28, n.2, p. 135-158, 2019.

TAKÁTS, A., TOSELLI, C. Estudio ambiental y turístico de la Reserva Natural Las Piedras, Gualeguaychú, Entre Ríos, Argentina. Tiempo de Gestión, Entre Ríos, n. 21, p. 13-52, 2016.

THE PLANT LIST 2013. Version 1.1. Disponible en: http://www.theplantlist.org/, Acceso 20 de mayo 2020.

TORANZA, C; BRAZEIRO, A.; HARETCHE, F. Distribución y diversidad del bosque serrano del Uruguay. En: Brazeiro, A. (Ed.), Recientes avances en investigación para la gestión y conservación del bosque nativo de Uruguay.Montevideo: Facultad de Ciencias y Ministerio de Ganadería Agricultura y Pesca, 2018, p 59-62.

TORRES, L.M. 1903. Los cementerios indígenas del sur de Entre Ríos y su relación con los de Uruguay, túmulos de Campana (Buenos Aires) y Santos (Brasil). Anales del Museo Nacional de Buenos Aires, Buenos Aires, 2s.3a, p. 57-73.

TORRES, L. M. Los primitivos habitantes del Delta del Paraná.Buenos Aires:Universidad Nacional de La Plata, Biblioteca Centenaria, 1911, 616 p.

TRILlO, C.; ARIAS TOLEDO, B.; COLANTONIO, S. Revisión de la etnomedicina en Argentina: construcción de la disciplina y perspectivas para el futuro. Bonplandia, Corrientes, v. 20, n. 2, p. 405-417,2011.

ZEBALLOS, E. Noticie sur un tumulus prehistorique de Buenos Aires. Revue d'Anthropologie, París, n 1, p. 577-583, 1878. 